MATTHEWS, Roger. "Una propuesta realista de reforma para las prisiones de Lationamérica".

Polit. crim. Vol. 6, № 12 (Diciembre 2011), Art. 3, pp. 296 - 338.

[http://www.politicacriminal.cl/Vol_06/n_12/Vol6N12A3.pdf]

\title{
Una propuesta realista de reforma para las prisiones en Latinoamérica ${ }^{*}$
}

\author{
Roger Matthews \\ Profesor de Criminología de la Universidad de Kent \\ R.A.Matthews@kent.ac.uk.
}

\section{Resumen}

Algunas prisiones en Latinoamérica han sido tildadas entre las peores del mundo. Human Rights Watch y el Comité de Naciones Unidas contra la Tortura han denunciado numerosas irregularidades en gran parte de los países latinoamericanos, entre las que destacan: hacinamiento, malas condiciones de habitabilidad, falta de seguridad, frecuentes motines y actos de violencia, así como ineficiencias en la gestión. La finalidad de este informe radica en destacar, no solo los problemas y abusos que describen las organizaciones de derechos humanos, sino también una serie de propuestas de reforma realistas. Este documento establece una serie líneas básicas de actuación destinadas no solo a la discusión científica, sino también a la acción política, así como, destaca las reformas que se están llevando a cabo en este sentido en varios países latinoamericanos. Estas propuestas aplicadas individual o colectivamente, pueden proveer un marco de referencia para una reforma penitenciaria progresista y, a la vez, factible que contribuya a la consecución de unas instituciones, por último, menos dañosas.

\section{Palabras clave}

Prisiones latinoamericanas, reforma penitenciara, realismo crítico

\begin{abstract}
Some prisons in Latin America have been described as being amongst the worst in the world. Reports by Hunan Rights Watch and the UN Committee Against Torture have provided a number of reports detailing the problems of imprisonment in many Latin American countries. The main problems involve overcrowding, poor conditions, and a lack of security, frequent riots and acts of violence, as well as problems of prison management. In this report the aim is to outline not only the problems and abuses described by human rights organisations but also to set out a series of realistic reform objectives. Perusing these objectives, either individually or collectively, it is suggested, can provide a framework for prison reform that is achievable and progressive. The report aims to provide a basis for both discussion and action and to stimulate existing efforts by various prison reformers in Latin America to make prisons a less, socially, individually and politically damaging institutions.
\end{abstract}

* Traducción realizada por José Ángel Fernández Cruz, Prof. de derecho penal de la Universidad Austral de Chile y Marisela Velázquez, doctoranda en Criminología de la Universidad de Kent, Reino Unido. 
MATTHEWS, Roger. "Una propuesta realista de reforma para las prisiones de Lationamérica".

\section{Key words}

Latin-American prisons, prison Reform, critical realism

\section{Una breve referencia al sistema penitenciario latinoamericano.}

El sistema penitenciario moderno fue introducido en gran parte de los países Iberoamericanos entre la segunda mitad del siglo XIX y primera mitad del siglo XX. Este periodo comenzó cuando en 1834 Brasil y Chile iniciaron los primeros proyectos de construcción de cárceles, y finalizó en 1939 con la incorporación de Cuba a los sistemas penitenciarios modernos.

Algunas prisiones, como las construidas en Lima (1862) y Quito (1875) se diseñaron conforme al modelo panóptico de Jeremy Bentham. Otros centros penitenciarios, como la Penitenciaría de Buenos Aires (1877), adoptaron el sistema radical, diseño que dominaría posteriormente en los sistemas penitenciarios latinoamericanos. ${ }^{1}$

La prisión fue una de las principales manifestaciones de la modernización del castigo. Constituyó en Europa y Norte América una de las formas del sistema de disciplina requeridos por el capitalismo industrial, ofreciendo una idea novedosa a la clase dirigente para resolver los conflictos surgidos de la nueva realidad social emergente, especialmente, en las ciudades. ${ }^{2}$ Sin embargo, la disciplina del trabajo, como idea central de los sistemas modernos penitenciarios, no tuvo tanta relevancia en los países Latinoamericanos en el siglo XIX debido a que en ese periodo sus economías eran esencialmente rurales. Al ser menos relevante esta función disciplinaria requerida en las grandes urbes, el nuevo modelo penitenciario fue visto como inadecuado. Por esta razón, los nuevos centros penitenciarios fueron destinados en sus inicios a lugares de confinamiento y detención, más que en centros de reforma y rehabilitación.

Guiados por el positivismo ideológico del siglo XIX el reformismo penitenciario intentó identificar las distintas tipologías criminales, donde la principal estrategia de tratamiento fue, en primer lugar, el aislamiento (en silencio) del preso para así favorecer la auto reflexión y, en menor medida, el trabajo y la educación. Mientras que en el siglo XX los esfuerzos para desarrollar los aspectos disciplinarios y reformistas de la prisión continuaron en países como Méjico y Costa Rica, en el resto de los países latinoamericanos la adopción de técnicas penitenciarias concurrió al lado del castigo corporal y de la pena de muerte, incluyéndose manifestaciones de la justicia privada. Debido a este especial contexto histórico y social, la introducción de la prisión en Latinoamérica ha sido calificada como una forma de «modernización tradicional», donde más que una transformación respecto de las ideas del antiguo sistema penitenciario las rediseñó y consolidó.

\footnotetext{
${ }^{1}$ Salvatore, R., AguirRe, C., The Birth of the Penitentiary in Latin America: University of Texas Press, 1996.

${ }^{2}$ FOUCAUlT, M., Discipline and Punish: The Birth of the Prison. London: Allen Lane, 1997. RUSCHE, G. y KIRCHEIMER, O., Punishment and Social Structure. New Brunswick: Transaction Books, 2003.
} 
Los países con un sistema de justicia inquisitorial tienen la tendencia de convertir las prisiones en instituciones destinadas a cobijar a los procesados a la espera de juicio. Por esta razón, una gran parte de la población penitenciaria en Latinoamérica se encontraba en prisión preventiva. De esta manera, las prisiones en vez de estar destinadas a "castigar el tiempo disciplinado", como sucedió en Europa y Norteamérica, gran parte de los establecimientos penitenciarios en Latinoamérica estuvieron destinados a la incapacitación y contención de los presuntos delincuentes. Como consecuencia de esta situación, ha existido un menor énfasis respecto de la rehabilitación a lo largo de la historia y, a la vez, se ha generado una extendida desilusión acerca de la potencialidad de la prisión en Latinoamérica como medio tanto para la resocialización del delincuente como para el aumento de la seguridad pública.

Latinoamérica no pasó por la era del capitalismo industrial, lo que supuso que no se aplicara el sistema fordista de producción y el posterior desarrollo del capitalismo social. El denominado Estado social introdujo en la mayoría de los países europeos y en Estados Unidos, lo que ha sido definido como la "sanción bienestarista" que supuso la aplicación de un mayor número de sanciones fundamentadas en la "inserción en la comunidad". 3 Así, gran parte del siglo XX estuvo caracterizado por la combinación de castigos de "inserción" y "exclusión", concretados por sanciones comunitarias y la prisión, respectivamente. La relativa ausencia en la historia penitenciaria latinoamericana de sanciones comunitarias conllevó a un crecimiento de las prisiones como un medio de inocuización, a pesar de que en muchos países desarrollados esta medida de control social era ya fuertemente cuestionada.

La peculiar historia del sistema penitenciario latinoamericano constituye uno de los mejores ejemplos para recordar que cualquier discusión relativa a la reforma penitenciaria debe encuadrarse dentro del contexto social e histórico de cada país latinoamericano, más que mimetizar sistemas y estudios procedentes de países desarrollados.

\section{La política penitenciaria.}

Se suele afirmar que la prisión no da votos. Los partidos políticos, de manera muy extendida, entienden que la prisión constituye un asunto de un precario rédito político. Por el contario, la educación y la salud son vistas como cuestiones de mayor interés a la hora de llevarlas al terreno de las campañas políticas.

Sin embargo, existe un creciente consenso en que cuestiones como el respeto de los derechos fundamentales, la seguridad jurídica y la eficacia de las prisiones tienen efectos, no solo en la población penitenciaria, sino también en la propia comunidad e imagen exterior del país así como en la de sus líderes políticos. Los gobiernos que permiten abusos y no ponen freno a la violación de derechos humanos son percibidos como débiles. La imposibilidad de administrar adecuadamente y de manera profesional un

${ }^{3}$ GARLAND, D., Punishment and Welfare: A History of Penal Strategies. Aldershot: Gower, 1985. DONZELOT, J., The Policing of Families. London: Hutchinson, 1979. 
sistema penitenciario es apreciada, tanto en el ámbito nacional como internacional, como un claro signo de una mala administración pública. Esta situación, como hemos mencionado, afecta a la imagen pública ante la comunidad internacional.

Numerosos estudios realizados en países occidentales muestran que la ciudadanía en general se muestra a favor tanto del castigo a los criminales como de su rehabilitación. Expresan su desacuerdo con el cumplimiento de penas de prisión cuando la amenaza a la comunidad ha desaparecido. Ahora bien, debemos tener presente que la práctica totalidad de los presos, cumplida sus respectivas penas, regresará a los mismos barrios marginadas de origen. Estas poblaciones son áreas con una alta tasa de criminalidad y, además, deben lidiar con graves problemas sociales. Por esta razón, la llegada de miles de presos, los cuales han sufrido graves experiencias en la cárcel, como consecuencia de una determinada política penitenciaria, y que regresan con menos posibilidades económicas que con las que ingresaron en prisión, solo conlleva una carga adicional a estas comunidades de por sí desfavorecidas socialmente.

La problemática de la reinserción de los presos en sus comunidades de origen ha supuesto un importante obstáculo para afrontar una reforma en la política penitenciaria. Por ende, la opción política que pueda ofrecer una política penitenciara más efectiva y, a la vez, más respetuosa con los derechos humanos estará en condiciones de aglutinar un mayor número de votos y un mayor apoyo de la comunidad y de los agentes sociales. La política penitenciaria latinoamericana, no cabe duda, que es una cuestión complicada desde el punto de vista estrictamente partidista, ya que una determinada reforma que tenga visos de ser eficaz, puede ser calificada tanto de progresista como de autoritaria.

Podría mantenerse que un sistema penitenciario brutal y represivo es una señal de la fortaleza de un determinado gobierno $\mathrm{y}$, que por el contrario, una mejora en las condiciones de los presos constituye una muestra de debilidad en la lucha contra la criminalidad, pero, de hecho, lo contrario es lo correcto. Una administración penitenciaria defectuosa no causa buena impresión a nadie, mientras que el desarrollo y mantenimiento de un sistema de prisiones adecuado y profesional es percibido como un compromiso social a la hora de incrementar la legitimación de las políticas públicas.

El problema de la corrupción en Latinoamérica afecta a muchos aspectos de la vida política y social, incluyéndose el sistema de justicia criminal. Sin embargo, la constante referencia a la problemática de la corrupción es utilizado con frecuencia como una excusa para no hacer nada y que, en último término, fomenta un sentimiento de derrotismo. La corrupción, sin duda, es un cáncer social, pero como una enfermedad puede ser curada o tratada. Incluso, en aquellos lugares donde la corrupción constituye un problema estructural, existen políticos decentes y responsables comprometidos con las reformas y el progreso social. Además, las alianzas con agencias, organizaciones e individuos dignos de confianza, donde no se actué principalmente por sus propios intereses o consignas partidistas, sino que tenga la firme convicción de mejorar, ayuda a la comunidad y a los propios servidores públicos. 
Lo señalado anteriormente no debe tildarse de iluso o de un excesivo optimismo. La reforma penitenciaria latinoamericana constituye un verdadero desafío. La necesaria reforma penitenciaria, como cualquier cambio social, no acontece de un día para otro, sino que, por el contrario, va a tomar varios años y un considerable ejercicio de responsabilidad y duro trabajo. Sin embargo, las recientes experiencias de países como Japón y Rusia, demuestran que un cambio sustancial en la política de prisiones resulta posible en un periodo razonable de tiempo, sin perjuicio de que algunos problemas subsistan todavía en la actualidad. ${ }^{4}$

\section{El objetivo de este informe.}

Este documento se centra en las prisiones y no en la reforma penal y procesal penal. Las discusiones sobre la reforma penitenciaria se han centrado con cierto exceso, en cuestiones relativas a la determinación de la pena y, en general, en la selección tanto legislativa como judicial de los condenados que deben ingresar en prisión. La reforma penitenciaria, en sentido estricto, constituye un proceso merecedor de una especial y separada consideración. La experiencia nos demuestra que las reformas en la determinación de la pena resultan per se un proceso incierto en cuanto sus objetivos $\mathrm{y}$, además, resulta necesario enfrentarse a las cuestiones que actualmente apremian a la reforma penitenciara.

Las únicas menciones relativas al proceso de determinación de la pena que serán consideradas en el presente informe serán aquellas directamente relacionadas con el encarcelamiento, especialmente, con la problemática del hacinamiento en las prisiones. A mayor abundamiento, el principal objetivo se centrará en las medidas que pueden tomarse en este momento para forjar unas instituciones menos dañosas y más constructivas.

De la misma manera, este informe no abordará la polémica relativa a las denominadas "alternativas a la prisión". Basta con decir que las "alternativas a la prisión" no han constituido la panacea en la política penitenciaria e, incluso, en muchos casos la introducción de nuevas alternativas han terminado por servir como alternativa a medidas alternativas ya existentes, más que una verdadera opción a la prisión. Como han puesto de manifiesto varios estudios existe un verdadero peligro de una "expansión ramificada" del poder punitivo, como consecuencia de la introducción de las nuevas alternativas a la prisión. ${ }^{5}$

El presente informe será desarrollado desde la perspectiva del realismo crítico. ${ }^{6}$ También

\footnotetext{
${ }^{4}$ PIACENTINI, L., Surviving Russian Prisons. Cullompton: Willan, 2004. HAMAI, K., "Prison Population in Japan: Stable for 30 Years", en TONRY, M., (ed.) Penal Reform in Overcrowded Times. Oxford University Press, 2001.

${ }^{5}$ COHEN, S., Visions of Social Control. Cambridge: Polity, 1985. MATTHEWS, R. "Alternatives to Prison: A Realist Approach", en: CARLEN, P., COOK, D. (eds.) Paying for Crime. Bristol: Open University Press, 1989.

${ }^{6}$ Véase una aproximación sobre el actual estado de discusión sobre el realismo crítico en: SAYER, A., Realism in Social Science. London: Sage, 2001; MATTHEWS, R., "Realist Criminology Revisited" en: McLAUGHLIN E., y NEWBURN, T., (eds.) The Sage Handbook of Criminological Theory. London: Sage, 2010.
} 
se tomará en consideración algunas cuestiones relacionadas con otras perspectivas críticas de la reforma penitenciaria: el abolicionismo y minimalismo. El abolicionismo, en su propósito de suprimir la prisión son generalmente escépticos sobre cuestiones relacionadas con la reforma penitenciaria, ya que entienden que las mejoras introducidas en las prisiones re-legitiman y perpetúan su propia existencia. El minimalismo, por otra parte, plantea una reducción drástica de la población penitenciaria. ${ }^{7}$ Ahora bien, no existe un parámetro objetivo para calcular cuántas personas deberían ingresar en prisión. Para el realismo crítico la reforma de las prisiones va más allá de un simple "juego de números", centrándose en responder quién debería ir a prisión, con qué finalidad y por cuánto tiempo.

Una aproximación realista de la reforma penitenciaria debe también distinguirse de las posiciones actuariales, centradas en la búsqueda de la mayor eficiencia en la gestión de la prisión. El realismo crítico va más allá de la mera gerencia de las prisiones e incorpora aspectos relativos a los derechos fundamentales y a la justicia social. El objetivo radica en encontrar y desarrollar un sistema penitenciario que sea beneficioso para la comunidad $\mathrm{y}$, especialmente, para los grupos sociales menos favorecidos. Como conclusión nuestro objetivo no radica simplemente en mostrar una visión crítica de la prisión, sino en desarrollar un enfoque que, por una parte, conecte social y políticamente con los problemas que realmente preocupan a la ciudadanía y, por otra, ofrezca un punto de referencia bienestarista a los poderes públicos.

\section{El marco de referencia.}

Este estudio ofrece diez directrices generales (véase infra) que ofrecen una visión progresista y, a la vez viable, de una reforma penitenciaria. Debemos advertir que no aparecen en un estricto orden temporal de cumplimiento ni que tampoco resulta absolutamente necesario cumplir todas estas directrices para su efectiva consecución. Ahora bien, estamos ante el típico caso de que a un mayor cumplimiento de determinados objetivos que se encuentran entre sí estrechamente relacionados, habrá un aumento recíproco de los beneficios e, incluso, fomentará la consecución de otras directrices que, en un principio, no estaban previstas en la agenda política. Pero en sentido contrario, estamos también ante el clásico proyecto político donde resulta difícil la consecución de todas las propuestas. En todo caso, su cumplimiento parcial per se puede producir importantes mejoras sociales.

Gran parte de estas propuestas no resultan nuevas en el debate político criminal y varias ya han sido emprendidas en diferentes países latinoamericanos. Lo novedoso de este informe radica en que ofrece una visión estructurada de estas propuestas de una forma más compresible y coherente que puede facilitar una reforma exitosa del sistema penitenciario.

\footnotetext{
${ }^{7}$ MATTHEWS, R. "Developing a Realist Approach to Penal Reform", en: LOWMAN J., MacLEAN, (eds.) Realist Criminology: Crime Control and Policing in the 1990s. Toronto: University of Toronto Press, 1992. MATTHEWS, R., "Rethinking Penal Policy: Towards a Systems Approach" en: MATTHEWS, R., YOUNG, J., (eds) The New Politics of Crime and Punishment. Cullompton: Willan, 2003.
} 
Las directrices son las siguientes:

1. Eliminación o reducción del hacinamiento en las prisiones.

2. Maximización del personal de seguridad.

3. Protección de los derechos fundamentales de los presos.

4. Instauración de un sistema de formación y trabajo que tenga sentido con la realidad social de la población penitenciaria.

5. La apertura de las prisiones a la ciudadanía y a las agencias sociales.

6. Profesionalización del personal penitenciario.

7. Desarrollo de un justo, consistente y apropiado procedimiento disciplinario.

8. Instauración de fiscalizaciones regulares a través de inspectores independientes.

9. Desarrollo de efectivos programas de rehabilitación.

10. Instauración de formas de custodia intermitentes (arrestos de fin semana o reclusión nocturna).

A partir de las reformas penales acaecidas en varios países, hemos perfilado estas diez directrices como las más relevantes a la hora de afrontar una reforma de las prisiones. Especial atención se prestará a los dos primeros objetivos, ya que el hacinamiento y la maximización de la seguridad en las prisiones constituyen los problemas más graves y extendidos a lo largo del continente latinoamericano.

\subsection{La reducción del hacinamiento.}

El hacinamiento constituye, sin lugar a dudas, unos de los rasgos distintivos de los sistemas penitenciarios iberoamericanos, especialmente en países como Brasil, Bolivia, Perú, Uruguay y Panamá. La sobrepoblación penitenciaria se puede manifestar de dos formas. La primera, cuando el número de presos resulta notoriamente superior a la capacidad que un determinado sistema penitenciario en su totalidad puede soportar y, la segunda, cuando cierto tipo prisiones -normalmente aquellas que albergan a procesados en prisión preventiva- tienen más internos que plazas disponibles.

Sin duda, el hacinamiento afecta a la vida en las prisiones y socava la posibilidad de aplicar cualquier medida positiva. Además, de los problemas más evidentes como la ausencia de un mínimo espacio vital y de los problemas derivados de la logística diaria, como la alimentación y o las actividades recreativas, el hacinamiento supone que:

- Los internos permanezcan más tiempo en sus celdas.

- Disminuya el acceso al trabajo y formación en las prisiones.

- Se incrementen los problemas de disciplina y seguridad.

- Aumente la tensión o violencia entre los internos.

- Se afecten las relaciones entre los internos y los funcionarios de prisiones.

Contamos con varias estrategias que pueden adoptarse a la hora de reducir el hacinamiento carcelario. El más obvio reside en la construcción de nuevas prisiones. Sin embargo, debemos tener presente que, como ha sucedido en Estados Unidos en las dos últimas décadas, la construcción masiva de establecimientos penitenciarios solo ha 
aminorado el nivel de hacinamiento, pero con un enorme costo económico. El aumento constante de plazas en las prisiones dan luz verde a los jueces y tribunales para continuar enviando a un número importante de condenados o procesados a la prisión. Y lo más grave es que una vez que las cárceles están construidas, estas son muy difíciles de remover o transformar.

En todo caso, y a pesar de la anterior crítica, la construcción de nuevos establecimientos penitenciarios en situaciones críticas de hacinamiento constituye una estrategia adecuada en el proceso de reforma penitenciaria. Pero no puede erigirse como la única solución, ya que además de no reducir de manera significativa el hacinamiento en la mayoría de las ocasiones solo contribuye a aumentar la población penitenciaria en términos absolutos a costo económico desmesurado.

El caso chileno constituye un buen ejemplo de una política penitenciaria fundamentada exclusivamente en la construcción de cárceles. Así, la instauración de seis cárceles privadas ha venido acompañada por un aumento del $44 \%$ la tasa de presos por cada 100.000 habitantes en la última década. Ante esta situación, no se ha encontrado mejor solución que aprobar la construcción de más prisiones privadas con la idea de atajar el creciente aumento de la población penitenciaria. ${ }^{8}$

Las prisiones privadas han sido objeto de una significativa crítica, especialmente, desde la constatación del fracaso a la hora de evitar o reducir la inversión del Estado en su gestión y mantenimiento. También han sido criticadas porque descorren el peligro de convertir a las cárceles en instituciones más automatizadas e impersonales. La principal justificación a favor del las cárceles privadas ha residido en que difieren los considerables costos de construcción. Para los gobiernos reacios a permitir empresas privadas en la construcción o gestión de los establecimientos penitenciarios una opción sería la formación de empresas públicas con participación de capital privado. Las empresas privadas participarían en la construcción y financiamiento de las instalaciones penitenciarias para después gestionarla con fondos estatales. Así, las compañías privadas tras asumir los costes de construcción recuperarían la inversión a través de contratos de gestión de las propias instalaciones. Esta última manifestación se ha producido en Francia, adoptada posteriormente por Chile.

Sin embargo, existen informes en Francia que han puesto de manifiesto deficiencias en la calidad de la construcción. En otros países, como Canadá y Gran Bretaña, los respectivos gobiernos han rescindido o finalizado los contratos a las empresas privadas debido, principalmente, a la mala calidad de la construcción de los edificios, la ineficiencia en la gestión de las cárceles y la falta de transparencia en su contabilidad. ${ }^{9}$

\footnotetext{
${ }^{8}$ Véase, CARRANZA, E., "Prison Privatization in Latin America" en: CARRANZA, E., (ed.) Crime, Criminal Justice and Prison in Latin America and the Caribbean. ILANUD. Costa Rica, 2008, http://www.ilanud.cr.cr

${ }^{9}$ NATHAN, S., "Prison Privatization: International Developments and Issues and the Implications for Latin America”, en CARRANZA, Crime, Criminal Justice, cit. nota n 8. HARDING, R., Private Prisons and Public Accountability. Buckingham: Open University Press, 1997.
} 
Estos cuestionamientos sobre la eficiencia y calidad de las denominadas cárceles privadas han acaecido también en Latinoamérica. En Puerto Rico en el año 2002, tras la construcción de tres prisiones gestionadas por compañías estadounidenses, se constató, posteriormente, que resultaba más barato la propia gestión por parte del Estado. De la misma manera, las prisiones privadas continúan desarrollándose en Chile, Honduras, Paraguay, Perú, Brasil, Argentina y México, a pesar de no existir una evidencia clara de que reduzcan considerablemente los costos de gestión, por una parte, y la reincidencia, por otra.

Por el contrario, más que centrarse en la construcción de más cárceles existen otras medidas para enfrentar el problema del hacinamiento. Así podemos destacar las siguientes:

- La instauración de tribunales penitenciarios y procedimientos sumarios.

- El establecimiento de plazos razonables en la duración del proceso penal y la prisión preventiva.

- El establecimiento de los denominados tribunales de tratamiento de presos drogodependientes.

- La instauración o incremento de los procedimientos abreviados y, en general, de la denominada justicia restaurativa.

- El arresto domiciliario y la custodia comunitaria.

- La amnistía.

- La adopción de medidas alternativas a la prisión y beneficios penitenciarios.

- Reubicación de los internos en otros establecimientos.

Estas medidas permiten regular el número de personas encarceladas $\mathrm{y}$, especialmente, las tres primeras resultan especialmente relevantes para reducir la población penitenciaria en prisión preventiva.

Los tribunales penitenciaros con procedimientos sumarios en materia penitenciaria (Fast track courts) fueron instaurados en India en 2001 e implantados de manera general en 2006. Tienen como finalidad la reducción de la ingente cantidad de internos que se encuentra en prisión preventiva a la espera de una resolución judicial -especialmente a los detenidos con penas más graves- a través de la aplicación de un procedimiento rápido y sumario. Están formados por jueces retirados, abogados y personal de la administración de justicia. A lo largo de la década anterior se han instaurado un total de 1.562 tribunales, resolviendo alrededor de 2.5 millones del total de los 3.5 millones de casos que les habían sido transferidos. Debemos señalar que, finalmente el costo de estos tribunales fue menor que el destinado al mantenimiento de los procesados detenidos innecesariamente. No obstante, ha habido problemas a la hora de reclutar el número suficiente de jueces y de recibir el necesario apoyo de la administración de justicia. A pesar de estas dificultades, quince nuevos tribunales han sido programados para tratar los casos de violaciones en Delhi, mientras que en la región de Mumbai hay otros cien tribunales en proyecto. ${ }^{10}$

${ }^{10}$ GANGAN, S., "Mararashtra Nod for 100 Fast Track Courts", Daily News and Analysis, Marzo 16, 2011. GRAHAM, D., "Fast Track Courts to Handle Rape Cases in the Capital", Centre For Social Research, 
El Consejo de Justicia brasileño $(\mathrm{CNJ})$ ha creado una institución de similares características denominado Mutirao, compuesto por jueces, fiscales, defensores y abogados de diferentes áreas, que tiene como tarea reexaminar los casos de prisión preventiva, priorizando, los supuestos más problemáticos. En noviembre de 2009 el CNJ anunció que, después de examinar 83.808 casos, había puesto en libertad a 16.466 personas que habían sido encarcelados irregularmente. También constató que 27. 644 habían sido sometidos a medidas de seguridad o cautelares inadecuadas. Esto sugiere que una significante proporción de la población penitenciaria en prisión preventiva no debió haber sido ingresada o mantenida en establecimientos penitenciarios. También, se detectó la tendencia de los jueces brasileños de encarcelar a acusados por delitos de bagatela, especialmente, pequeños hurtos o robos. Con carácter general podemos afirmar que una parte importante del Poder Judicial brasileño parece haber abandonado el principio de presunción de inocencia. ${ }^{11}$ Ante esta situación, en algunos estados, asociaciones compuestas por estudiantes, profesores de derecho y abogados voluntarios prestan servicios legales a internos en prisión preventiva.

Otros tribunales especializados, como los denominados jueces de proximidad, destinados a pequeñas disputas o controversias pueden también contribuir a reducir la población penitenciaria.

Otra estrategia ha consistido en reformar el límite y duración de la prisión preventiva. Así, en la India, se debe poner en libertad al interno si este ha permanecido en prisión en el periodo de tiempo máximo por el delito que fue acusado. Así, aquellos acusados por delitos con penas relativamente bajas y que, previsiblemente, la sentencia le condenaría con una pena de menor duración del tiempo que tiempo que ya cumplido bajo en prisión preventiva podrían ser liberados. Esta medida fue adoptada por Venezuela en 1999, pero no ha sido seguida por la mayoría de los países latinoamericanos. En otros países, como Argentina y Costa Rica, han establecido unos límites a la prisión preventiva y superados estos los detenidos deben ser puestos en libertad. El problema que se plantea es que estos límites han sido establecidos con términos vagos e imprecisos, como «un tiempo razonable» o simple o llanamente no son cumplidos.

Alrededor de la última década han sido implantados en EE.UU., Australia y Canadá los denominados tribunales de tratamiento de presos drogodependientes (Drug Courts). ${ }^{12}$ Sólo en Estado Unidos operan, por el momento, aproximadamente 2.000 tribunales. Estas instituciones ofrecen la posibilidad al interno de abandonar el establecimiento penitenciario con la condición de someterse a un tratamiento intensivo de rehabilitación.

New Delhi, India, 2011. Véase también, Home Office Border Agency, Country of Origin Information Report, India, 2010.

${ }^{11}$ International Bar Association, One in Five: The Crisis in Brazil's Prisons and Criminal Justice System. International Bar Association Human Rights Institute Report, 2010.

${ }^{12}$ Office of National Drug Control Policy, Painting the Current Picture: A National Report Card on Drug Courts and Other Problem Solving Programs in the United States, 2010. http://www.whitehousedrugpolicy_gov/enforce/drugcourt,html . WALKER, J., International Experience of Drug Courts. The Scottish Executive Scottish Research Unit, Edinburgh, 2001. HUCKLESBY, A. y WINCUP, E., Drug Interventions in Criminal Justice. Open University Press, 2010. Transnational Institute, System Overload: Drug Laws and Prisons in Latin America, 2010. 
La estrecha relación entre el consumo de drogas y la comisión de delitos constituye una de los principales problemas en muchos establecimientos penitenciarios. Incluso, la propia encarcelación puede generar o intensificar la adicción a las drogas. Estos tribunales especializados permiten que los presos condenados por delitos relacionados con su drogodependencia sean tratados fuera de los establecimientos penitenciarios. Estos tratamientos pueden acarrear unos costos adicionales respecto de los establecidos en las propias cárceles, pero no cabe duda de los beneficios de todo tipo que pueden acarrear, no solo respecto a la reducción de la población penitenciaria, sino también en términos de reincidencia. Estos tribunales también pueden contribuir a la disminución del hacinamiento teniendo presente en sus decisiones los niveles de consumo y tráfico de drogas. Debemos recordar que como resultado de la "guerra contra las drogas" muchas personas fueron encarceladas por delitos de microtráfico o consumo de drogas. Así, aquellos internos procesados o condenados por delitos de tráfico de drogas menos graves podrían así evitar la prisión preventiva o, en su caso, ser liberados con las condiciones de tratamiento adecuadas.

La justicia restaurativa viene siendo utilizada por una gran parte de los ordenamientos jurídicos como mecanismo para reducir el tiempo en los procesos penales y para moderar la respuesta penal en aquellos casos en que el acusado se declara culpable o reconoce los hechos alegados por la acusación. Medidas, como la suspensión condicional del procedimiento, son beneficiosas tanto para el acusado como para el sistema judicial en su conjunto. Se ha estimado que en Estados Unidos alrededor del 90\% de los casos que ingresan al sistema judicial se les aplicó alguna medida alternativa. ${ }^{13}$ Resulta evidente que si estos casos se hubieran sometido a los procedimientos penales ordinarios del sistema judicial estadounidense este hubiera colapsado. A pesar de lo anteriormente expuesto, existen críticas contra estas medidas como, por ejemplo, su afectación al principio de legalidad procesal penal y a una supuesta incitación a la indulgencia por parte de los tribunales de justicia penal. Si bien, podría aceptarse como válidas algunas de las críticas formuladas a estos mecanismos de negociación, la realidad es que los procedimientos ordinarios de justicia penal resultan altamente negociados e individualizados y las sentencias no se fundamentan con exclusividad a los simples hechos, sino que, por el contrario, también son una respuesta a la disposición, grado de cooperación y remordimiento mostrados por el ofensor.

Otras medidas relacionadas con la justicia penal negociada son las medidas o penas alternativas a la prisión. Estamos ante una estrategia política criminal ampliamente adoptada en numerosos países y que, sin duda, resulta provechosa para la reducción del hacinamiento penitenciario. Sin embargo, existe una creciente renuencia o miedo a la aplicación de estas medidas en países como Estados Unidos y Reino Unido, como consecuencia del menoscabo que puede generar en la confianza hacia el sistema judicial, incluso, a la protesta ciudadana, especialmente respeto de los delitos más graves o de mayor connotación social.

\footnotetext{
${ }^{13}$ BOLL, M., Plea Bargaining and Agreement in the Criminal Process: A Comparison between Australia, England and Germany, Verlag, 2009. VOGEL, M., Coercion and Compromise: Plea Bargaining, The Courts and the Making of Political Authority. Open University Press, 2007.
} 
En Estados Unidos el uso general de la libertad condicional ha generado graves problemas a la hora de controlar su cumplimiento, que ha supuesto que muchos condenados han regresado a la cárcel por el incumplimiento de las condiciones impuestas en la aplicación de la libertad condicional distintas a la comisión de un nuevo crimen. ${ }^{14}$ Sin embargo, el uso de sistemas electrónicos en el Reino Unido está siendo eficaz en el control y cumplimiento de la libertad condicional. También, la posibilidad de condicionar los beneficios penitenciarios a la buena conducta del interno, por ejemplo, con su contribución a la convivencia dentro de las prisiones ayuda a reducir la población penitenciaria.

Podemos encontrar varios ejemplos de estas medidas en Latinoamérica. En Perú entre 2000 y 2001 se establecieron medidas para poner en libertad a numerosos presos condenados en prisión preventiva, especialmente, en aquellos casos donde las resoluciones judiciales carecían de una sólida fundamentación probatoria y jurídica. Colombia en 1997 liberó a todos los internos que habían cumplido el 60\% de la condena. Ecuador puso en libertad aproximadamente al 40\%de los presos condenados por posesión o trafico de pequeñas cantidades de drogas. ${ }^{15}$

El arresto domiciliario, también denominado como custodia comunitaria, ha sido adoptado en algunos países como Nueva Zelanda, Finlandia y Canadá. La racionalidad de uso del confinamiento domiciliario radica en que aísla al ofensor, evita los efectos criminógenos de la prisión y permite relacionarse con la familia y la comunidad. La regulación del arresto domiciliario puede ser más o menos restrictiva y se puede utilizar para determinadas categorías de delincuentes, normalmente, para sustituir penas de prisión de corta o mediana duración. En Finlandia su uso se encuentra generalizado hasta tal punto que dos tercios de aquellos que deberían haber ingresado a prisión les fueron aplicados estas medidas o pena sustitutiva. Por otra parte, en Nueva Zelanda la aplicación del arresto domiciliario resulta menos frecuente, requiriéndose para su aprobación tanto un proceso judicial como administrativo. En Canadá se aplica para sentencias condenatorias de hasta dos años de prisión. Se ha estimado que la aplicación de esta pena sustitutiva ha reducido la población penitenciaria en 55.000 personas (13\%) en un periodo de tres años. Véase, por lo tanto, que tanto en Canadá como en Finlandia la aplicación del arresto domiciliario ha reducido de manera importante la población penitenciaria. ${ }^{16}$

En algunos ordenamientos jurídicos, como el italiano, francés y sudafricano, se recurren a amnistías periódicas con el fin de recudir la población penitenciaria y, en especial, para lidiar con la presión del hacinamiento. Aunque no cabe duda que constituye una manera

\footnotetext{
${ }^{14}$ PETERSILIA, J., When Prisoners Come Home: Parole and Prisoner Reentry, Oxford University Press, 2003.

${ }^{15}$ UNGAR, M., "Prisons and Politics in Latin America", Human Rights Quarterly Vol. 25, N 4 (2003), pp. 909-34. UNGAR, M., y MAGOLINI, A., "Latin America's Prisons: A Crisis of Criminal Policy and Democratic Rule", en: Bergman, M., WhITEHEAD, L., (eds) Criminality, Public Security and the Challenge to Democracy in Latin America. Indiana: University of Notre Dam Press, 2009.

${ }^{16}$ HOUGH, M., ALLEN, R. y SOLOMON, E., Tackling Prison Overcrowding. Bristol: The Policy Press, 2008 .
} 
rápida para reducir el número de internos, tiende a ser arbitraria y contraria a los fines de la pena. Además, suele aparecer o percibirse como una respuesta ante una crisis de hacinamiento, más que una medida racional y coherente en el marco de la reforma penitenciaria.

Otra opción para reducir la sobrepoblación penitenciaria es la denominada custodia intermitente, principalmente, la prisión nocturna y el arresto de fin de semana. Se le permite al interno durante el día o los días laborables trabajar o realizar cursos de formación en el exterior, regresando en las noches o fines de semana al establecimiento penitenciario. En Italia, por ejemplo, alrededor del $70 \%$ de la población penitenciaria que está en situación de prisión preventiva se les aplica la pena de prisión nocturna. Esta medida será tratada con una mayor profundización en apartado posterior.

Finalmente, alguna mención debe hacerse a las medidas de reinserción después de cumplida la pena privativa de libertad. Resulta conocido que las tasas de reincidencia resultan extremadamente altas en la mayor parte de los países, pero a la vez, viene siendo una evidencia que el empleo y el alojamiento resultan esenciales para el efectivo desistimiento criminal. En numerosos países se viene realizando un esfuerzo considerable en la implantación de programas de reinserción social. En este sentido cabe destacar, los acuerdos con empresas privadas para contratación de ex presidiarios, ${ }^{17}$ bajo la cobertura de algún tipo de seguro que ofrezca protección a los empleadores.

Si bien, resulta un hecho que la población penitenciaria ha aumentado en los últimos tiempos en gran parte de los países latinoamericanos, también debemos señalar que ha habido una importante reducción en otros países. Así por ejemplo, en Nicaragua se ha producido una significante reducción de presos en la última década como consecuencia de la implantación de medidas de reinserción y de penas alternativas a la prisión. Otro ejemplo, lo encontramos en el caso panameño donde el establecimiento de una serie de reformas han tenido unos efectos muy positivos. Así:

"En el caso de Panamá, la reducción de la población penitenciaria entre 2007 y 2008 se debe a los siguientes medidas: (1) El Poder Judicial aplicó la libertad condicional con la finalidad de agilizar los procesos judiciales contra acusados en prisión preventiva, con el resultado de que muchos ciudadanos que estaban en prisión preventiva fueron posteriormente declarados inocentes. (2) El sistema penitenciario implantó a partir de 2005 una agresiva política de redención de penas por trabajo o educación (...). (3) La limitación de la prisión preventiva como consecuencia de una política penitenciara a favor de medidas cautelares alternativas. (4) La concesión de beneficios penitenciarios tales como el arresto domiciliario para enfermos terminales o gravemente enfermos, la libertad condicional y la repatriación de presos extranjeros. Estos cuatros factores son los que han contribuido en gran medida a la reducción de aproximadamente 2000 personas en $2008 \% .{ }^{18}$

17 HUCKLesby, A., HAGLEY-DICKENSON, L., Prisoner Resettlement: Policy and Practice. Cullompton: Willan, 2007.

${ }^{18}$ Citado por CARRANZA, "Prision", cit. nota n 8, p. 59. 
Tras la lectura de este apartado, se puede comprobar la existencia de un elenco de medidas que, aplicadas de manera coordinada, pueden reducir el hacinamiento carcelario. Por el contrario, debemos recordar que la construcción de nuevas cárceles por sí misma, con independencia de si son gestionadas pública o privadamente, no parece resolver satisfactoriamente este problema. En conclusión, una estrategia efectiva para reducir el hacinamiento debe ser multidimensional y coordinada.

\subsection{La optimización de la seguridad.}

La cárcel para muchos presos constituye una verdadera pesadilla, especialmente para aquellos presos más vulnerables. Constituyen lugares peligrosos donde la intimidación, el abuso sexual en todas sus posibles manifestaciones y el acoso están ampliamente extendidos. Así, como ha puesto de manifiesto Rosa del Olmo respecto de las cárceles latinoamericanas:

"En nuestros países los presos enfrentan dos tipos de castigos. El primero, es el establecido por la ley, aunque en ocasiones no sea aplicado. El segundo castigo, no proviene de los textos legales ni de las cortes de justicia, sino que aparece en la convivencia diaria de las prisiones administrado por los otros internos o funcionarios de prisiones, en la forma de violaciones, abusos de todo tipo, extorsiones, robos, torturas o asesinatos". 19

Para una gran parte de los internos la vida en la prisión supone una segunda sentencia que puede llegar a ser mucha más dañina y peligrosa que la propia pérdida de libertad. El abuso está estrechamente relacionado con las grandes prisiones, donde los guardias operan a «distancia» y las relaciones personales con los internos son mínimas. Cuando la administración permite a los internos que gobiernen algún ámbito o espacio de la prisión, existe un riesgo evidente de que ciertos grupos abusen y controlen a los internos más vulnerables. Existe siempre una propensión a controlar e intimidar por parte de los presos con mayor poder, especialmente físico, y por los que forman parte de bandas o pandillas. Enfrentarse a estos abusos de poder y proveer de una adecuada seguridad dentro de las prisiones deben constituir una prioridad para la administración penitenciaria. Resulta inaceptable, por tanto, que se tolere la corrupción y el abuso en las prisiones. Aquellos gendarmes o personal de la administración penitenciaria que no sean capaces de ofrecer unas mínimas condiciones de seguridad deben ser apartados y, en su caso, sometidos al imperio de la ley.

Podemos señalar dos grandes aproximaciones en materia de seguridad penitenciaria: los sistemas de seguridad física y los de seguridad dinámica. Los primeros son los más fáciles de implantar y se centran en la vigilancia y diseño de las prisiones. Estudios de victimización han puesto en evidencia la existencia de «puntos calientes», donde se concentran gran parte de los problemas de seguridad en las cárceles. Los sistemas de prevención situacional han demostrado ser eficaces a la hora de reducir las oportunidades

${ }^{19}$ DEL OLMO, R., "The State of Prisons and Prisoners in Four Countries in the Andean Region", en: WEISS, R., SOUTH, N., (eds.), Comparing Prison Systems. Amsterdam: Gordon and Breach Publishers, 1998. 
a la hora de cometer algún tipo de violencia. Los circuitos cerrados de televisión y las alarmas pueden prevenir actos violentos y ofrecer una adecuada vigilancia en la totalidad de los espacios de la prisión. ${ }^{20}$

En cuanto a los sistemas de seguridad dinámicos, las rutinas y hábitos en la vida de las prisiones y las relaciones con el personal penitenciario constituyen sus aspectos centrales. La gestión de los potenciales conflictos, necesariamente, requiere de la mayor y más completa información sobre la vida en las prisiones que, sin duda, resulta mucho más fácil si se cuenta con unas buenas relaciones entre los internos y el personal penitenciario. Por el contrario, cuando las relaciones son distantes o inexistentes, el personal penitenciario tiende a aplicar formas de comunicación impersonal, como la vigilancia y los registros, entorno que fomenta la desconfianza de los internos y socavan las posibles relaciones proactivas entre ellos. ${ }^{21}$ Por el contrario el uso «no-oficial» de la violencia por parte de los guardias de prisiones estimula todo tipo de violencia y la formación de grupos de resistencia. ${ }^{22}$

Los problemas de inseguridad y su intensidad pueden variar dependiendo del tipo de prisión y de internos. Algunas investigaciones han demostrado que el número de asaltos y otros incidentes graves pueden reducirse con cambios en el régimen y diseños de las prisiones. Así, por ejemplo, unidades más pequeñas pueden favorecer una mayor autonomía y responsabilidad de los internos y, de esta manera, reducir la violencia. El recurso de estrictas medidas de seguridad y cierre de celdas y de otros espacios han reducido el número de asaltos, en especial, los apuñalamientos.

Las pandillas o bandas constituyen una de las principales amenazas a la seguridad dentro de las prisiones. Controlan ciertas actividades, particularmente, el tráfico de drogas, la extorsión a otros presos y suelen verse envueltos en peleas con otras bandas. En el año 2010, por ejemplo, diez internos de la prisión de Toronco, Venezuela, murieron como consecuencia de un tiroteo entre bandas rivales. De acuerdo con varios informes, los internos utilizaron armas automáticas y granadas de manos durante las ocho horas que duró la batalla. Otro tiroteo dejó treinta muertos en el centro de detención de Benfica, Río de Janeiro. Resulta, cuando menos chocante, que la revuelta terminará solo cuando el pastor Marcos Pereira intervino y pudo persuadir a los internos de deponer su actitud. Muchos otros ejemplos podríamos ofrecer para afirmar que los disturbios, asaltos, muertes o lesiones protagonizados por bandas en las prisiones se han convertido en uno de los principales rasgos de las prisiones latinoamericanas en las últimas décadas. La situación ha llegado hasta tal punto que los jóvenes que son ingresados en un centro de detención juvenil brasileños y que no pertenecen a ninguna banda, son ubicados en una de ellas. Como resulta conocido, es frecuente que convivan bandas rivales en la misma

\footnotetext{
${ }^{20}$ BOTTOMS, A., "Interpersonal Violence and Social Order in Prisons", en: TONRY, M., y PETERSILIA, J., (eds.), Prisons. Chicago: University of Chicago Press, 1999. EDGAR, K., O’DONNELL, I., y MARTIN, C., Prison Violence: The Dynamics of Conflict Fear and Power. Cullompton: Willan, 2003.

${ }^{21}$ PARKER, M., Dynamic Security: The Democratic Therapeutic Community in Prison. London: Jessica Kingsley, 2007.

${ }^{22}$ COOKE, D., "Containing Violent Prisoners: An Analysis of the Barlinnie Special Unit", British Journal of Criminology Vol. 29, № 2 (1989), pp.129-43.
} 
MATTHEWS, Roger. "Una propuesta realista de reforma para las prisiones de Lationamérica".

institución penitenciaria. ${ }^{23}$ Claramente, esta situación constituye un caldo de cultivo para futuras tragedias.

El impacto de una banda en una prisión dependerá del número de personas involucradas y del compromiso de sus miembros. En general, existen dos estrategias que pueden ser adoptadas para regular las actividades de las bandas en las prisiones: las autoridades pueden iniciar un "guerra de desgaste" o una "guerra de manipulación". 24

Una «guerra de desgaste» supone un enfrentamiento continuo entre la administración penitenciaria y las bandas, que va acompañado de encierros en celdas de castigo, todo tipo de sanciones disciplinarias, registros regulares, confiscación de teléfonos móviles e, incluso, la utilización de agentes encubiertos. Estas estrategias con frecuencia lo único que consiguen es incrementar el antagonismo -acabando con cualquier tipo de colaboración de las bandas con las autoridades- y generar una espiral de violencia con bajas en ambos frentes. ${ }^{25}$

En Guatemala como consecuencia del intento de recuperar una de sus prisiones controladas por bandas, dieciocho oficiales de prisiones fueron asesinados en tres años en las calles de la Ciudad de Guatemala ${ }^{26}$. Quizá este tipo de guerras de desgaste pueda tener éxito, pero conlleva unos grandes costos sociales y todo tipo de sufrimientos, incluidas pérdidas de vidas humanas, además de generar una tensión dentro de las prisiones que en cualquier momento puede derivar una motín o revuelta.

Por otro lado, la "guerra de manipulación" supone la adopción de una estrategia más elaborada. Las dos medidas más importantes que se pueden adoptar son el aislamiento y concentración de los miembros de la banda o, por el contrario, su dispersión. Los integrantes de una banda pueden ser agrupados y asilados limitándoles su capacidad para controlar o intimidar al resto de los internos que no pertenecen a una pandilla. De manera alternativa, la dispersión de los miembros de una banda en diferentes prisiones a lo largo del país puede servir para reducir su poder. En algunos casos, esta medida puede conllevar su traslado a prisiones alejadas de su zona de control. Por último, también se puede adoptar un sistema regular de traslados de los miembros de la banda a través de diferentes prisiones con el fin de evitar el control que puedan ejercer en una específica

23 BBC News, Ten Die in Venezuela Prison Gang Battle. www.bbc.co.uk/news/world-latin-america11439683, 2010. SYLVESTRE, M-E., "The Vicious Cycle of Violence: Prison Riot at the Benfica House of Detention in Rio de Janeiro", The Harvard Review of Latin America, 2005. Véase, KNOX, G., The Problem of Gangs and Security Threat Groups in American Prisons. National Gang Research Centre, 2005; COHEN, M. y RUBIO, M., "Violence and Crime in Latin America. Solutions", documento preparado para la Consulta de San José. http://www.iadb_org/document.cfm?id=1186239, 2007; JACOBS, J., Stateville: The Penitentiary in Mass Society (chapter 6). Chicago: University of Chicago Press, 1977; Human Rights Watch: Brazil "Real Dungeons": Juvenile Detention in the State of Rio de Janeiro Vol. 16, $\mathrm{N}^{\circ} 7$ (2004).

${ }^{24}$ Esta distinción ha sido tomada de Antonio Gramsci. GRAMSCI, A., Prison Notebooks. New York: Nowell, Smith and Hoare, 1971.

${ }^{25}$ Véase el Capítulo 3 en: MATTHEWS, R., Pagando Tiempo: Una Introducción a la Sociología del Encarcelamiento: Ediciones Belllaterra, 2003.

26 Gaceta Penitenciaria, Número 08 (2011), Ministerio de Gobernación. 
prisión.

Otro de los aspectos positivos de la concentración y aislamiento de los miembros de una banda radica en la posibilidad de emplear personal especializado para este tipo de delincuencia. A lo anterior, debemos añadir que, de acuerdo con investigaciones realizadas, las prisiones es tierra fértil para reclutar nuevos miembros. Por tanto, el aislamiento de los líderes y principales miembros puede limitar su capacidad de reclutamiento de nuevos miembros entre los internos para la banda criminal. La elección de una política eficaz de aislamiento o de dispersión dependerá de la naturaleza, tamaño y estructura de la banda.

Una medida que puede ser vista como punto de referencia fue la adoptada en Irlanda del Norte durante el periodo "The Troubles", 27 donde los terroristas convictos fueron reclasificados, no como criminales, sino como "prisioneros políticos". ${ }^{28}$ Fueron tratados como una categoría especial de prisioneros, donde se les concedió una mayor autonomía y responsabilidad en el funcionamiento de las prisiones. Aunque los integrantes de bandas no suelen ser considerados como terroristas -aunque algunos consideran que sí lo son- comparten algunas características. Por ejemplo, sus actividades ilícitas son consecuencia directa de las órdenes de los líderes o, simplemente, de las obligaciones contraídas con la banda. Estamos también ante organizaciones jerarquizadas que poseen sus propios códigos de conducta y sistemas disciplinarios $\mathrm{y}$, por tanto, constituyen una categoría especial de delincuentes, que requieren una respuesta diferenciada por parte de las instituciones públicas. En el mismo sentido, que en el caso de Irlanda del Norte, varias prisiones en Estados Unidos han adoptado repuestas imaginativas, como por ejemplo, la ubicación de los miembros de una banda en unidades separadas, donde se les concede un cierto grado de autonomía que permite minimizar los conflictos cotidianos dentro de la prisión. De esta manera, guardias y otros internos no son objetos de todo tipo de coacciones y amenazas y, a la vez, se favorece que el resto de los miembros de las bandas puedan llevar una vida con un cierto orden. Por supuesto, que estas medidas no suponen el otorgamiento del total control de las prisiones a las diferentes bandas que pueden albergarse en una prisión, sino más bien el establecimiento de una forma de control que reconoce las diferentes motivaciones de los presos y relaciones con una particular organización. Estas organizaciones con sus propias reglas y estructuras pueden generar un ambiente menos dañoso. En todo caso, estas medidas pueden ser monitoreadas a fin de determinar si son realmente efectivas. En conclusión, la problemática de las bandas continúa siendo un grave problema que amenaza a la seguridad de las prisiones en su totalidad.

Aparte de las medidas destinadas a la problemática de las bandas existen programas penitenciarios destinados a la violencia interpersonal. Así, por ejemplo, una variedad de terapias, especialmente los programas de autocontrol de conductas violentas, vienen

\footnotetext{
${ }^{27}$ Término coloquial utilizado para denominar el conflicto en Irlanda del Norte que comenzó a finales de los años 1960 y finalizó en 1998 con la firma de los Acuerdos de Belfast (N. del T).

${ }^{28}$ MCEVOY, K., Paramilitary Imprisonment in Northern Ireland: Resistance, Management and Release; Oxford University Press, 2011. TOMLINSON, M., "Imprisoned Ireland", en: RUGGERIO, V., RYAN, M. y SIM, J. (eds.) Western European Penal Systems: A Critical Anatomy. London: Sage, 1995.
} 
teniendo un existo aceptable en diferentes países. En Gran Bretaña, desde hace mucho tiempo los comités terapéuticos han reducido las conductas violentas de los presos, incrementando la seguridad en general. En este sentido, existe un creciente interés en las técnicas de mediación y justicia restaurativa para tratar los conflictos dentro de las prisiones. Como venimos manteniendo en este informe, resulta de vital importancia evaluar tanto los programas de tratamiento como los propios sistemas de evaluación. Necesitamos saber no solo lo que funciona sino también cómo y por qué funciona. Pero, en todo caso, no debemos olvidar que la victimización y la protección de presos más vulnerables constituyen también una cuestión de derechos fundamentales.

\subsection{Defendiendo los derechos fundamentales.}

Existen dos razones principales a la hora de proteger los derechos fundamentales en las prisiones. La primera, porque resulta lo correcto para aquellos preocupados por la justicia social y la segunda, porque afecta directamente en la legitimidad y funcionamiento de las instituciones penitenciarias. ${ }^{29}$ La gestión de las prisiones está sujeta a un número de convenios y tratados internacionales destinados al cumplimiento de unos estándares mínimos de protección de los derechos fundamentales. Debemos recordar que los establecimientos penitenciarios son servicios públicos como las escuelas y los hospitales $\mathrm{y}$, por tanto, deben estar destinadas al bien común. Las personas que son enviadas a prisión como castigo no para castigarlas, es decir, la prisión tiene por objeto la privación de libertad y no el abuso y el maltrato de los presos.

Los internos pierden ciertos derechos como, por ejemplo, el derecho al sufragio. El Convenio de Naciones Unidas relativo a los estándares mínimos de tratamiento de presos (1957) prohíbe cualquier forma de tortura o malos tratos y requiere por parte de las autoridades penitenciarias condiciones mínimas en el tratamiento físico de los internos y protección de salud, prohibiendo expresamente cualquier tipo de abuso psíquico o emocional. La protección a la salud también incluye, además, una condiciones mínimas de higiene corporal y habitabilidad. Además, debemos señalar, que existen otros acuerdos internacionales que contienen otras obligaciones destinadas a la protección de los derechos fundamentales de los presos destinados al respeto y mantenimiento de su dignidad.

Resulta bien conocido que las prisiones en Latinoamérica poseen una mala reputación en la protección de los derechos fundamentales. Reportes de Naciones Unidas y organizaciones humanitarias como Human Rights Watch vienen denunciado con regularidad graves vulneraciones de estos compromisos internacionales. Así, por ejemplo, la citada organización no gubernamental en su informe del año 2011 ha denunciado que:

\footnotetext{
${ }^{29}$ Véase, COYLE, A., A Human Rights Approach to Prison Management. London: International Centre for Prison Studies, 2002.
} 
Polit. crim. Vol. 6, № 12 (Diciembre 2011), Art. 3, pp. 296 - 338.

[http://www.politicacriminal.cl/Vol_06/n_12/Vol6N12A3.pdf]

"Las prisiones venezolanas son de las más violentas en Latinoamérica. Falta de seguridad, infraestructuras deterioradas, hacinamiento, funcionarios penitenciarios insuficientemente formados y la corrupción ha permitido que bandas armadas hayan tomado el control de las prisiones. Cientos de muertes violentas ocurren cada año". 30

En el mismo reporte se establece respecto de Argentina que:

"El hacinamiento, abusos por parte de los guardias y la violencia entre internos continúa siendo un grave problema en los establecimientos penitenciarios y de detención. En un conocido fallo de la Corte Suprema Argentina de 2005, tras poner de manifiesto las deplorables condiciones en las cárceles de la provincia de Buenos Aries, insta a las autoridades a cumplir con las reglas mínimas establecidas por el Convenio de Naciones Unidas". 31

En el caso de Chile, el Informe de 2009 de Human Rights Watch manifiesta:

"A pesar de la apertura de seis nuevas prisiones privadas, el hacinamiento continúa siendo un serio problema. Así, por ejemplo, en 2008 el Centro de Detención Preventiva Santiago Sur, diseñado para una capacidad de 3.170 plazas, albergaba a 6.256 internos. En muchos de los establecimientos más antiguos su higiene y sanidad resultan pésimas. Los internos, en ocasiones, son recluidos en oscuras celdas sin ventilación y sin provisiones higiénicas y sanitarias por hasta10 días". ${ }^{32}$

El Informe Especial sobre la Tortura y otros Tratos o Penas crueles, Inhumanos o degradantes relativo a las condiciones carcelarias en Uruguay, publicado en marzo de 2009, a pesar de no hallar ninguna evidencia de tortura, concluye:

"La condiciones de la Prisión Libertad resultan particularmente horrorosas, donde los presos y detenidos en prisión preventiva están recluidos como animales en cajas de metal por casi 24 horas al día e, incluso, obligados a beber de los sanitarios o retretes, debido a las restricciones de agua". ${ }^{33}$

Lo que resulta chocante de estos informes es que ya no escandalizan a la mayoría de la población. Por supuesto, Latinoamérica no está sola en el tratamiento inadecuado y, en ocasiones, degradante hacia los presos. Incluso, existen otros países que sufren menos pobreza y que no ofrecen unos mínimos estándares de protección de los derechos fundamentales en las prisiones. Sin embargo, aunque las prisiones sean instituciones costosas, existen unos costos sociales y económicos procedentes de la violación de los derechos fundamentales que superan con creces estos costos monetarios. Otros países

30 Human Rights Watch, World Report Venezuela, 2011, http://www.hrw.org/en/world-report2011/Venezuela

31 Human Rights Watch, World Report. Argentina, 2011, http://www.hrw.org/en/world-report2011/argentina Sobre las condiciones de las prisiones en Argentina, Brasil y Chile, véase: SALLA, F. y BAllesteros, P., Democracy, Human Rights and Prison Conditions in South America. University of Sao Paulo, Brazil, 2009. http://www.udhr60.ch

32 Human Rights Watch, World Report. Chile, 2009, http://www.hrw.org/en/world-report/2009/chile

${ }^{33}$ UN News Centre, UN Rights Expert Urges Uruguay to End Appalling Prison Conditions, 2009. Véase también, MANZ, B., Central America: Patterns of Human Rights Violations. Writenet. University of California: Berkeley, 2008. 
latinoamericanos podrían señalarse en este sentido, pero las anteriores citas resultan suficientemente ilustrativas para afirmar que la vulneración de los derechos humanos constituye una de las principales lacras de los sistemas penitenciarios latinoamericanos.

Como consecuencia de los tratos crueles e inhumanos, los presos tienen poco que perder a la hora de involucrarse en motines y disturbios. Tenemos varios ejemplos de esta situación en Latinoamérica en los últimos años, donde muchas personas han muerto o han sido heridas, produciéndose grandiosos daños materiales, e, incluso la completa destrucción de las prisiones. ${ }^{34}$

Incluso, la propia experiencia cotidiana de abusos crea tensión y conflictos. Todo acto de brutalidad o injusticia deslegitima el sistema penitenciario, donde las autoridades políticas resultan en último término responsables. La legitimidad de las prisiones no solo es socavada ante los ojos de los presos y sus familias sino también ante el resto de la ciudadanía.

En Estados Unidos y Europa se ha producido un movimiento a favor de los derechos de los presos que ha tenido una importante influencia en el proceso de reforma del sistema penitenciario. A pesar de que el movimiento a favor de los derechos de los presos perdió fuerza durante los años noventa, se ha producido un resurgimiento en los últimos años. ${ }^{35}$

En Estados Unidos reclamaciones en contra de las penas crueles e inhumanas, de manera particular a través de la denominada acción popular, ${ }^{36}$ han tenido una especial relevancia en las reformas penitenciarias. La activa implicación de los tribunales estadounidenses a favor de los derechos humanos de los presos ha puesto de manifiesto que la reforma de las prisiones no se ha producido, como debería haber sido, en la arena política sino en la judicial. Por ejemplo, las cortes federales están examinando el sistema penitenciario como nunca había sucedido con anterioridad.

La experiencia de los Estados Unidos ha demostrado que un movimiento a favor de los derechos de los presos bien organizado puede generar una mayor protección por parte de los tribunales de justicia, como por ejemplo, a través de un mecanismo de conciliación; o sensibilizar a la opinión pública sobre las condiciones en las cárceles. Hasta 1960 los presos estadounidenses eran considerados como "esclavos del estado", pero a partir del Movimiento por los Derechos Civiles los presos están más concienciados y, por tanto, con mayor predisposición en las defensa de sus derechos fundamentales.

\footnotetext{
${ }^{34}$ BBC News, Ten Die in Venezuela, cit. nota $n^{\circ} 23$. SYLVESTRE, "The Vicious Cycle", cit. nota $\mathrm{n}^{\circ} 23$. KNOX, G., The Problem of Gangs, cit. nota ${ }^{\circ}{ }^{23}$. COHEN/RUBIO, "Violence and Crime", cit. nota ${ }^{\circ}$ 23.

${ }^{35}$ JACOBS, J., "Prison Reform Amid the Ruins of Prisoners' Rights", en TONRY, M., (ed.) The Future of Imprisonment: Oxford University Press, 2004.

${ }^{36}$ Mediante la acción popular penal (class action) se permite a los ciudadanos o personas jurídicas que no se encuentran directamente afectados por el delito o controversia instar la actuación de la administración de justicia en defensa de intereses colectivos o difusos (N. del T).
} 
Durante los años 70 Estados Unidos se vio obligado a cambiar el sistema de salud pública en las cárceles como consecuencia de varios fallos de los tribunales federales. Así, a través de la contratación de empresas privadas de salud y la adquisición de material sanitario en grandes cantidades con el fin de abaratar los costos, las autoridades penitenciarias fueron capaces de mejorar de manera significativa la atención médica de los internos.

Las campañas a favor de la protección de los derechos de los presos deben formar parte, necesariamente, de las campañas para la protección de los derechos fundamentales en general. Varios convenios internacionales han sido firmados para alcanzar unos estándares mínimos en la protección de los derechos fundamentales de los presos, pero muchos países latinoamericanos en los albores del siglo XXI no los han cumplido. No obstante, existen ejemplos alrededor del mundo donde se ha producido un importante avance en el reconocimiento, protección y defensa de los derechos fundamentales de los presos.

\subsection{Proporcionando un trabajo con sentido.}

Existen dos aspectos fundamentales en la disciplina del mercado laboral relacionados con las prisiones que se encuentran en una permanente tensión: la cárcel reafirma en la mayoría de las ocasiones la marginalización de aquellos que ya se encuentran degradados en mercado laboral, y, al mismo tiempo, se intenta inculcar una disciplina laboral como mecanismo de reinserción social. ${ }^{37}$ Por tanto, una reforma penitenciaria debe hacer frente a esta tensión que existe en el mismo corazón del sistema penitenciario. Ante la marginalización de la prisión, la mayoría de los reformistas entienden que el trabajo en las prisiones ofrece a los internos unas actividades potencialmente constructivas que contribuyen al orden y a la reducción de la reincidencia.

Se puede afirmar que existe un elemento normalizador del trabajo en las prisiones. Para la mayor parte de la población el trabajo constituye una rutina a lo largo de sus vidas $y$, con frecuencia, con labores monótonas y mal pagadas. Resulta comprensible que no cause buena impresión a la ciudadanía informes o noticias que muestran a los prisioneros desocupados u ociosos viviendo a costa del Estado. Así, desde la concepción victoriana (less eligibility) que propugnaba peores condiciones para los mendigos, prostitutas y niños residentes en las casas de trabajo respecto de la clase baja trabajadora, los ciudadanos no ven con buenos ojos que parte de sus impuestos se destinen a personas ociosas. ${ }^{38}$ Existen, por supuesto, grandes problemas a la hora de organizar el trabajo en las prisiones. La población penitenciaria suele tener una pobre educación, adolece de cualificación profesional $\mathrm{y}$, por tanto, posee una escasa o básica experiencia laboral que se ha centrado en los empleos de peores condiciones laborales. Estos antecedentes conllevan, en muchos casos, a una falta de motivación e interés por el trabajo colectivo que suele realizarse en las instituciones penitenciarias. Al mismo tiempo, hay una considerable resistencia en convertir a las prisiones en industrias destinadas a explotar a

\footnotetext{
${ }^{37}$ Véase, MATTHEWS, Pagando tiempo, Capítulo V, cit. nota n ${ }^{\circ} 26$.

${ }^{38}$ Principio introducido por Ley contra la Pobreza de 1834 en Gran Bretaña. Véase, RUSCHE, Georg (et alii), Punishment and social structure, Columbia University Press, 1939.
} 
mano la obra barata. Además, el trabajo en las prisiones supone, normalmente, actividades manuales y repetitivas que finalizan en productos o mercancías de poca importancia. Aunque existen límites a la hora de ofrecer un trabajo de calidad destinado a la reinserción de los presos, en muchas ocasiones no supone una forma menos tediosa de pasar el tiempo que el de la mayoría de los trabajadores en el medio libre. ${ }^{39}$

Existen dos opciones destinadas a incrementar la participación en el trabajo. La primera opción consiste en permitir a los presos trabajar fuera de las prisiones durante el día, especialmente, los detenidos en prisión preventiva. El trabajo diurno podría ser usado para delitos de poca gravedad, así como a aquellos que se encuentran en la última etapa de cumplimento de la pena. Esta medida no solo ofrecería una gran variedad de empleos a los presos, sino también contribuiría a la reducción del hacinamiento durante el día. Y por último, permitiría que los presos que no pudieran disfrutar de este beneficio penitenciario tuvieran mayores oportunidades para conseguir un trabajo en mejores condiciones dentro de la prisión.

La segunda opción consiste en involucrar a compañías privadas en la formación y búsqueda de empleo de los internos. Esta medida ha sido adoptada en algunas prisiones de Estados Unidos con buenos resultados. Por ejemplo, en una prisión de California los internos realizan parte de las reservas de una de las principales aerolíneas del país, recibiendo a cambio una remuneración. En la Patagonia argentina se les permite a los presos cultivar productos en una granja a extramuros del recinto penitenciario para su propio consumo y venta.

Brasil también ha tomado medidas a la hora de incrementar las oportunidades laborales en las prisiones, especialmente, para los presos que se encuentran en la última etapa de cumplimiento de la condena. Actualmente, unos 87.000 presos se ocupan en trabajos voluntarios, donde a cambio reciben una pequeña remuneración $\mathrm{y}$, al mismo tiempo, se les reduce el tiempo de condena. A la vez, se ha incrementado el número de escuelas en las prisiones donde su asistencia permite también reducir o remitir la condena. ${ }^{40}$

No debemos caer en la utopía de pensar que estas medidas destinadas a ofrecer un empleo útil vayan a tener éxito para la mayoría de los presos. Pero en todo caso, debemos intentar que el mayor número de internos se involucren en un trabajo acorde la realidad del mercado laboral que le permita respetarse a sí mismo y, de esta forma, reciban, a su vez, la aprobación de la ciudadanía por su esfuerzo. En lugares donde el trabajo no sea posible, la educación es la mejor opción para preparar a los presos para su futura incorporación al mundo laboral. Por ejemplo, profesores externos pueden ser invitados a las prisiones, así como permitir a los internos que asistan a cursos extramuros de los recintos penitenciarios. De cualquier manera, la formación ayudará los presos a conseguir un mejor empleo y calidad de vida.

\footnotetext{
39 PARENTI, C., Lockdown America; Police and Prisons in the Age of Crisis. London: Verso, 1999.

${ }^{40}$ International Bar Association, 2010.
} 


\subsection{La apertura de las prisiones a las agencias no gubernamentales, medios de comunicación y público en general.}

Resulta obvio que durante los últimos veinte años las prisiones, al menos en Europa y Estado Unidos, han dejado de ser una fortaleza aislada del exterior, especialmente, respecto de los medios de comunicación. Esta apertura se ha manifestado desde varias perspectivas. En primer lugar, numerosas agencias, asociaciones y personas han traspasado las puertas de las prisiones incrementándose la transparencia y responsabilidad de las autoridades penitenciarias. De esta manera, las prisiones pueden transformase en instituciones más accesibles y transparentes si se permite que "varios ojos" puedan observar su funcionamiento y hablar con los presos y los funcionarios de prisiones.

En segundo lugar, la participación de agencias y asociaciones procedentes de los servicios legales y del voluntariado supone una inyección de pericia y experiencia en la gestión y el día a día de las prisiones. Así, existen servicios legales extra penitenciarios que podrían aportar un importante apoyo a las prisiones. De igual manera, las organizaciones no gubernamentales podrían visitar o trabajar con los internos en diferentes proyectos y actividades. Y por último, las denominadas inspecciones externas así como la promoción de visitas de los familiares y amigos podrían ayudar a la disminución de su aislamiento y a la transparencia de su gestión y actividades. La apertura de las prisiones a la ciudadanía disminuye el aislamiento y promueven transparencia que resultan imprescindibles para los que "viven tras las rejas".

En tercer lugar, y lo más importante, la apertura de las prisiones a un amplio abanico de ciudadanos rompe las barreras existentes entre las prisiones y la comunidad. Sin duda, una intensa participación de la comunidad en el control, gestión y apoyo a las prisiones reduciría el estigma social y marginalización de los presos.

Respecto de los medios de comunicación, por ejemplo, resulta ilustrativo que no fueran invitados a visitar las prisiones británicas hasta hace veinte años. Hasta ese momento las prisiones eran lugares secretos para la opinión pública. Sin embargo, desde hace dos décadas, tanto en EE.UU. como en el Reino Unido, se vienen realizando un nuevo tipo de documentales (fly-on-the-wall documentaries) ${ }^{41}$ que han permitido que el público en general esté mejor informado sobre la realidad y problemática en las prisiones. Los programas de televisión, sin duda, han cambiado la percepción de la opinión pública sobre los «criminales». En la mayoría de los casos, la concurrencia de los medios de comunicación han ayudado a cambiar la vieja percepción de que los criminales son peligrosos y violentos, por otra percepción, cada vez más extendida, de que estamos ante personas mucho "más normales" de lo que muchos ciudadanos piensan. Un alto porcentaje de casos son personas con problemas que personas problemáticas. También es el caso que frente a las cámaras de televisión el personal penitenciario está más expuesto $\mathrm{y}$, necesariamente, tendrá más cuidado en su forma de actuar y comportarse. Los medios de comunicación son, necesariamente, selectivos y sesgados, pero, en todo caso, ayudan a la compresión y fiscalización de la vida en las prisiones.

\footnotetext{
${ }^{41}$ Podemos definirlos como aquellos reportajes, donde se pretende actuar con la mayor discreción posible a fin de mostrar un retrato lo más realista posible (N. del T.).
} 
En términos generales, el objetivo de una mayor participación de la ciudadanía y los agentes sociales en la gestión y fiscalización de las prisiones reside en el incremento de la transparencia y responsabilidad de las instituciones penitenciarias. La apertura de las prisiones a la comunidad, por sí sola, genera una enorme presión a las autoridades penitenciarias a la hora de "limpiar su actos", mejorar los servicios y la forma de relacionarse con los internos. Por último, una adecuada participación de los medios de comunicación permite a las autoridades penitenciarias difundir y exponer sus logros en la gestión y rehabilitación de los presos.

\subsection{Contracción y formación de profesionales en las prisiones.}

El trabajo de gendarme de prisiones no resulta fácil ni envidiable. En no pocas ocasiones resulta estresante y peligroso, en especial, en prisiones hacinadas y con pocos recursos. Por esta razón, la contratación de funcionarios de prisiones altamente cualificados y su posterior formación deberían ser unas de las prioridades de la política penitenciaria. Una especial consideración debe tomarse a la hora de determinar quién resulta apto para esta clase de trabajos que conllevan responsabilidades tan especiales. El personal penitenciario debe poseer unas específicas cualidades y una especial integridad personal. Con demasiada frecuencia la selección de los gendarmes y demás personal se realiza sin apenas una previa selección. Además, su posterior formación y supervisión resultan cuando menos superficial. El resultado de una falta o inadecuada selección y formación continua del personal penitenciario conlleva a una considerable volatilidad y absentismo laboral. La política de recursos humanos resulta indeterminada y suele recurrir a estrategias coercitivas y poco imaginativas. La moral entre los funcionarios bajo estas condiciones tiende a ser baja y afecta negativamente a la hora de contratar nuevo personal cualificado. $^{42}$

Un ejemplo de esta situación podemos encontrarlo en la política de contratación de ex militares o, incluso, de personas que no han podido acceder a la policía, como funcionarios de prisiones. Así, el trabajo en las prisiones es considerado por muchos como el último recurso a la hora de buscar un empleo. Al mismo tiempo, los departamentos de recursos humanos de las prisiones tampoco tienen muy claro el perfil profesional de los diferentes miembros del personal penitenciario que quiere contratar. Esta situación se evidencia con toda su crudeza en el hecho de que en muchos países no se requiere que los funcionarios de prisiones posean una especial cualificación profesional y cuando son contratados la necesaria formación especializada brilla por su ausencia. Incluso, en lugares donde existen programas de formación tampoco se tiene muy claro para qué se les está preparando. En otras palabras, existe poca claridad y cierta ambigüedad en la determinación del perfil profesional de los distintos funcionarios de prisiones. Por una parte, son normalmente denominados como "guardias" o "gendarmes", poniendo, por tanto, el punto de atención en las funciones de seguridad y custodia de los internos y, por otra, se espera de ellos que contribuyan con su trabajo a la rehabilitación de los presos. La dificultad de esta tarea, por tanto, es encontrar la manera de combinar

${ }^{42}$ CRAWLEY, E., Doing Prison Work: The Public and Private Lives of Prison Officers. Cullompton: Willan, 2004. 
estas dos principales funciones o roles del personal penitenciario de una manera estable y justa. $^{43}$

La formación profesional del personal penitenciario puede generar importantes implicaciones en la reforma penal. Las asociaciones o sindicatos de funcionarios de prisiones históricamente han venido presionando por una mejora en las condiciones materiales y humanas en los recintos penitenciarios. Por ejemplo, Asociación Americana de Correccionales tiene una larga tradición a la hora de colaborar en la mejora de la situación de las cárceles estadounidenses. En vez de ser vistos como los enemigos de los presos en un continuo conflicto, los funcionarios penitenciarios más cualificados tratan de mejorar sus propias condiciones de trabajo y de crear una ambiente laboral más seguro. En la actualidad, resulta más común en Estados Unidos que los funcionarios de prisiones posean formación universitaria. También resulta frecuente que se denominen a sí mismos como profesionales del sector público que tienen como principales objetivos la seguridad y las mejoras de las condiciones de vida de las prisiones. Un funcionario adecuadamente formado resulta menos propenso en verse envuelto en batallas inútiles y sin sentido con los presos por el simple hecho de reafirmar su autoridad. ${ }^{44}$

Cuando los presos son simplemente depositados o almacenados, las condiciones de trabajo de los funcionarios resultan precarias y estresantes. Varios estudios han puesto de manifiesto que el personal de prisiones quiere superar su percepción de simples "guardianes" y realizar un trabajo más gratificante dirigido a resolver los problemas de una manera constructiva junto con los presos. El uso de la fuerza como la principal vía para mantener el orden resulta degradante para los funcionarios de prisiones con una adecuada formación profesional $\mathrm{y}$, por el contario, se sienten orgullosos cuando tratan a los presos con respeto y justicia.

Los funcionarios de prisiones cualificados saben mejor que nadie que la manera más eficaz para conseguir el bienestar y el orden en las prisiones pasa por unas buenas y constructivas relaciones con los internos. El trabajo en una continua situación de tensión y conflicto resulta emocionalmente difícil de soportar, incluso para los funcionarios más duros. Los funcionarios veteranos saben que el trabajo resulta mucho más manejable si se desarrollan fluidas vías de comunicación y entendimiento personal con los presos. Debe existir un equilibrio, por una parte, entre el cumplimiento del orden y la justicia y el ejercicio de cierta flexibilidad y discrecionalidad, por otra. Los funcionarios que ejercitan una cierta discrecionalidad a la hora de aplicar la reglamentación penitenciaria están bien considerados y respetados, recibiendo a cambio cooperación por parte de los presos. En otras palabras, un buen funcionario de prisiones es aquel que sabe aplicar con sentido común la normativa penitenciaria. Por el contrario, en aquellas prisiones donde no pueda aplicarse cierta discrecionalidad en el cumplimiento de la normativa penitenciaria se corre el grave riesgo de que las bandas tomen el control de las cárceles. En otras palabras, una exigente contratación y una adecuada formación de los funcionarios de prisiones constituyen unas de las mejores medidas para evitar estos escenarios tan peligrosos.

\footnotetext{
${ }^{43}$ CRAWLEY, Doing Prison Work, cit. nota ${ }^{\circ} 42$.

44 JACOBS, M., Downsizing Prisons; How to Reduce Crime and End Mass Incarceration. New York University Press, 2005.
} 
Pero a la vez, los funcionarios de prisiones necesitan para realizar su trabajo una reglamentación clara y precisa, una estricta disciplina y una fiscalización regular de sus actividades. Aquéllos que cometan alguna conducta prohibida o ilegal deben ser sancionados y, en su caso, apartados de sus funciones.

\subsection{Un régimen disciplinario justo y efectivo.}

Las prisiones han sido diseñadas como «instituciones totales» aisladas de la vida cotidiana de la comunidad y la familia. Consecuentemente, existen asuntos sobre los derechos de los prisioneros, pautas de conductas y sanciones que deben estar regulados. Sin embargo, este es el caso donde el Estado de derecho no se detiene en las puertas de las prisiones, sino por el contrario, los presos tienen el mismo derecho a ser protegidos de la misma manera que aquellos que se encuentran a extramuros de ella.

Las prisiones, sin embargo, poseen sus propios códigos de conducta y prácticas y, por tanto, deben estar sometidos a un régimen disciplinario especial. Dos son las cuestiones claves en la consecución de un régimen disciplinario justo y efectivo. Por una parte, las relaciones entre el régimen penitenciario y el cumplimiento del Estado de derecho dentro de las prisiones $\mathrm{y}$, por otra, la manera en que los procedimientos son regulados $\mathrm{y}$ respetados por los internos.

Las directrices mínimas a nivel internacional sobre los regímenes penitenciarios disciplinarios sugieren lo siguiente:

- Tanto las sanciones como los procedimientos deben ser publicados y accesibles a los internos.

- Los presos deben tener el derecho a ser oídos antes de la imposición de una eventual sanción.

- Debe establecerse de manera clara y precisa, tanto las conductas que son sancionadas, como las sanciones que pueden ser aplicadas.

- Los procesos sancionadores deben ser juzgados por una autoridad independiente de la administración penitenciaria.

Estas directrices están destinadas a la consecución de unas sanciones disciplinarias justas, proporcionadas $\mathrm{y}$, además, coherentes con otros casos similares. El problema, sin embargo, aparece a la hora de concretar estas recomendaciones.

Las clases de infracciones que pueden ocurrir en las prisiones pueden sistematizarse en tres grandes categorías:

1. Actos de violencia incluyéndose todo tipo de amenazas y coacciones.

2. La participación en economías ilegales, como el tráfico de drogas o contrabando.

3. Actos de desobediencia o insubordinación. 
La concreción de estas clases de infracciones variará entre los diferentes sistemas penitenciarios y su concreta aplicación será determinada por los principios y prioridades de cada prisión. En los casos donde exista un desproporcionado número de infracciones similares, las autoridades deberán prestar atención, no solo al comportamiento de los presos, sino también a cómo los funcionarios de prisiones responden a las conductas de los internos y aplican el régimen penitenciario. Debemos tener presente que una elevada cantidad de infracciones puede derivar en comportamientos de desobediencia e insubordinación. En muchas ocasiones una falta de comunicación o estrategia entre los funcionarios de prisiones y los internos pueden causar o alentar estos tipos de comportamientos. Por el contrario, fluida comunicación entre los funcionarios de prisiones pueden arrojar más información sobre las que la aportada por los propios comportamientos de los internos. En las prisiones donde se presenta una aplicación del régimen disciplinario claramente desigual y desproporcionado debería realizarse una investigación de las causas de esta situación.

Se suele presumir que los presos comenten con frecuencia infracciones dentro de las prisiones y, por tanto, necesitan de rígida disciplina. Sin embargo, debería recordarse que una gran parte de las infracciones tienen su fundamento en la propia naturaleza y características de las prisiones y no son sancionadas en el medio libre, como por ejemplo, el uso de un teléfono celular.

Como ha puesto de relieve parte de sociología en el ámbito de las prisiones, no resulta posible sancionar todas las infracciones y, por tanto, existe un considerable grado de discreción que el personal penitenciario puede utilizar. Por esta razón, muchos incidentes en las prisiones tendrán necesariamente que acudir a formas de resolución de conflictos informales. $^{45}$

Con independencia de si los conflictos o incidentes son resueltos a través de métodos informales o a través de procedimientos disciplinarios, resulta necesaria una aplicación coherente, justa y proporcionada. Los mecanismos de decisión deben ser tan transparentes como sea posible y sometidos a la fiscalización de observadores independientes.

Los observadores o fiscalizadores independientes pueden participar de diferentes maneras en los procesos disciplinarios dentro de las prisiones. En primer lugar, la utilización de comisiones independientes compuestas por miembros de la comunidad o de los cuerpos profesionales. En segundo lugar, la instauración de juzgados o cortes disciplinarias independientes de la administración penitenciaria, compuesto por miembros de la judicatura. En tercer lugar, la creación de un defensor del pueblo de prisiones que tendría como misión recibir las quejas y denuncias relativas a la aplicación de las sanciones disciplinarias. En muchos países, incluidos algunos latinoamericanos, los defensores del

${ }^{45}$ Véase, SPARKS, R., BOTTOMS, A. y HAY, W., Prisons and the Problem of Order: Oxford; Clarendon, 1996. KING, R. y McDERMOTT, K., The State of Our Prisons, Oxford, 1995. CLARENDON y LIVINGSTONE, S., "The Changing Face of Prison Discipline", en: PLAYER, E., y JENKINS, M. (eds.) Prison After Woolf: Reform Through Riot. London: Routledge, 1994. 
MATTHEWS, Roger. "Una propuesta realista de reforma para las prisiones de Lationamérica".

pueblo tienen como uno de sus principales cometidos la fiscalización de las prisiones.

Donde los procesos y sanciones disciplinarias son percibidas injustas existe el riesgo de aumentar el antagonismo y la tensión entre los presos y el personal penitenciario, en otras palabras, una pérdida de respeto a las autoridades de prisiones que socava la legitimidad del propio sistema de prisiones.

A modo de resumen, las cuestiones que necesitamos responder acerca de los regímenes disciplinarios son las siguientes:

1. ¿Son coherentes en su concreta aplicación?

2. ¿Son justas y proporcionadas?

3. ¿Son públicas y transparentes?

4. ¿Existen mecanismos de fiscalización independientes, tribunales o mecanismos de revisión de las sanciones disciplinarias impuestas a los presos?

5. ¿Su aplicación fomenta el respeto a las autoridades penitenciarias?

Cuando las autoridades penitenciarias aplican con excesivo rigor el régimen disciplinario o imponen sanciones arbitrarias envían un claro mensaje sobre su falta de voluntad por conseguir un sistema sancionador justo y racional. Los presos, ante esta situación, justifican o reafirman sus propios ilícitos sobre la base de las malas prácticas a la hora de aplicar el régimen sancionador en un lugar, paradójicamente, diseñado para la reinserción social.

A pesar de las dificultades a la hora de desarrollar un sistema sancionador justo y, a la vez, efectivo, podemos constatar que en Europa, Estados Unidos y otros países han implementado regímenes disciplinarios mucho más equitativos y proporcionados. Este cambio político penitenciario ha servido también para trasparentar las prácticas disciplinarias.

\subsection{La instauración de fiscalizaciones regulares por parte de inspectores independientes.}

La propia estructura y diseño de las prisiones tiende a convertirlas en instituciones ocultas a la sociedad y reacias al escrutinio público. Por estas razones, resulta necesario articular mecanismos periódicos de fiscalización respecto de las condiciones $\mathrm{y}$ actividades en las prisiones. Como hemos mencionado con anterioridad, varias organizaciones internacionales, como Human Rights Watch y el Comité de las Naciones Unidas contra la Tortura, han puesto de manifiesto las deplorables condiciones de muchas prisiones latinoamericanas.

Estos informes aportan un valioso conocimiento sobre el estado de las prisiones, poniendo en evidencia la violación de derechos humanos relacionados con el tratamiento de los presos. A la vez, estos informes sirven como mecanismo de presión a los gobiernos y a las autoridades penitenciarias para cumplir con sus compromisos internacionales. Aunque, no hay duda que estas organizaciones aportan una valiosa información sobre el 
estado de las prisiones que, en gran parte, no sería posible de acceder, están sujetas a varias limitaciones. La primera reside en que las autoridades y representantes políticos debido a que estos informes están elaborados por organizaciones externas- pueden percibir que estas organizaciones no comprenden en su totalidad la realidad y dificultades a las que se enfrentan en las prisiones. En segundo lugar, y relacionado con la anterior afirmación, estas organizaciones suelen proponer medidas que, aunque bien intencionadas, resultan difíciles de implementar. En tercer lugar, estos informes suelen tomar como referencia aquellas prisiones sobre las cuales se sospecha que existe alguna irregularidad $\mathrm{y}$, por tanto, en muchas ocasiones sus informes son incompletos y asistemáticos. Y, en cuarto lugar, con la intención de iluminar sobre las deficiencias de las prisiones previamente seleccionadas se presta menos atención sobre los eventuales progresos y el considerable esfuerzo que las autoridades penitenciarias han hecho a la hora de afrontar los graves problemas a los que se enfrentan en sus prisiones.

Junto con los mencionados informes de las agencias internacionales, existen otras formas de fiscalización independiente, como por ejemplo, las investigaciones llevadas a cabo por académicos y periodistas en aquellos países (claro está, donde se les permita el acceso a las prisiones). Estas investigaciones suelen utilizar una metodología más analítica y, en el caso de que las personas que las han realizado participen en debates sobre la reforma en las prisiones lo harán con una información mejor contrastada. Sin embargo, al igual que sucede con los informes de las agencias internacionales, estas investigaciones suelen ser selectivas y las visitas carecen de la regularidad necesaria y, tampoco no resulta extraño que las autoridades hagan caso omiso de sus conclusiones y recomendaciones.

El informe del Representante Especial de las Naciones Unidas sobre Brasil realizado en 2007 destacó:

"Existen muchas agencias que tienen la capacidad de investigar las condiciones en las prisiones, pero ninguna de ellas realiza su cometido de manera adecuada. Estas deficiencias en las fiscalizaciones externas permiten que continúen las pobres condiciones y abusos en las prisiones".

Concluyendo que:

"De las varias instituciones establecidas por ley para fiscalizar las condiciones en las prisiones, debe destacarse de manera especial a los jueces de ejecución penal que en su mayoría son incapaces o, simplemente, fracasan a la hora de cumplir con sus obligaciones de manera adecuada". 46

Brasil ratificó en 2007 el Protocolo Facultativo de las Naciones Unidas de la Convención en Contra de la Tortura y Otros Tratos o Penas Crueles, Inhumanas o degradantes. En el artículo 1 del Protocolo Adicional se establece que:

${ }^{46}$ Preliminary Report by the Special Rapporteur on Extrajudicial, Summary or Arbitray Executions. Philip Alston Addendum, Mission to Brazil. November 2007. UN Doc.A/HRC/8/3/Add.414 May 2008. 
"El objetivo del presente Protocolo es establecer un sistema de visitas periódicas a cargo de órganos internacionales y nacionales independientes a los lugares en que se encuentren personas privadas de su libertad, con el fin de prevenir la tortura y otros tratos o penas crueles, inhumanos o degradantes".

Así, como consecuencia de la ratificación de este protocolo, Brasil estableció el Programa Nacional de Seguridad con la Ciudadanía que tiene como objetivos la erradicación de la corrupción y la tortura dentro de las prisiones y la propia seguridad de los ciudadanos, los jueces también tienen competencias en la fiscalización de las prisiones y son formalmente responsables de realizar inspecciones periódicas. Sin embargo:

"Sólo algunos jueces cumplen sus responsabilidades en la inspección de las prisiones y cuando se llevan a cabo se suelen realizar de manera superficial. [Como se ha discutido con anterioridad] estos sistemas de fiscalización no considerados como imparciales e independientes por los presos y, por tanto, tienen miedo de denunciar sus quejas a ellos. Esta situación, no solo supone una violación de las obligaciones internacionales contraídas por el Estado brasileño en la protección de los derechos fundamentales, sino también de propio derecho interno y de su constitución". ${ }^{7}$

Además del control judicial, los consejos de prisiones municipales (Conselho Penitenciario) y los consejos de comunidades locales (Conselho da Comunidade) también juegan un papel en la fiscalización de las prisiones. A lo anterior debemos añadir que varios estados brasileños han creado la figura del defensor de las prisiones. Los consejos de comunidades locales deben visitar cada uno de los establecimientos penitenciarios, entrevistar a los prisioneros y presentar informes mensuales, pero en la práctica muchos estados no los han creado y donde existen no reciben los mínimos recursos necesarios. Asimismo, sus miembros, con frecuencia, no tienen tiempo o interés en estos consejos. A lo anterior debemos añadir que las autoridades penitenciarias han denegado el acceso a estas instancias de fiscalización y cuando se realizan los resultados son raramente publicados $\mathrm{y}$, al mismo tiempo, se puede apreciar falta de coordinación entre las diferentes instituciones implicadas en la fiscalización.

Por supuesto, Brasil no es el único país que tiene un limitado y descoordinado sistema de inspección. De hecho, Brasil se ha esforzado, quizá de manera más intensa que otros países latinoamericanos, por implementar y mejorar un sistema de fiscalización de sus prisiones. Al menos, se ha tomado la decisión de crear un sistema local y nacional de inspección, lo que ha supuesto que hayan empezado a involucrarse por sí solo en este proceso, más que acudir a los organismos internacionales.

Amnistía Internacional ha reconocido que la creación del defensor de las prisiones ha traído ciertas mejoras en algunos estados brasileños, aunque no siempre poseen los suficientes recursos y competencias para alcanzar sus objetivos. ${ }^{48}$ También recomienda el

\footnotetext{
${ }^{47}$ International Bar Association, cit. nota $\mathrm{n}^{\mathrm{o}}$ 11. Sobre los efectos de una inadecuada fiscalización de los centros de detención juveniles, véase Human Rights Watch, en: In the Dark: Hidden Abuses Against Detained Youths in Rio de Janeiro. June, Vol. 17, No. 2 (B), 2005.

${ }^{48}$ Amnesty International (2007) Index, AMR 19/023/2007. Véase también UGGLA, F., "The Ombudsman in Latin America", Journal of Latin American Studies Vol. 36, № 3 (2004), pp. 36-50.
} 
establecimiento de un organismo, compuesto por especialistas penales, dedicado a realizar inspecciones periódicas, muchas de ellas sin previo aviso, utilizando un método consecuente con objetivos bien definidos. Las fiscalizaciones deberían realizarse por representantes del gobierno y de la comunidad.

Esta última recomendación toma como referencia el modelo de inspección adoptado por Gran Bretaña y que parece haber tenido una relativa eficacia. El modelo opera con dos sistemas de fiscalización. Uno está compuesto por personal civil dedicado a la inspección regular de un determinado establecimiento penitenciario. El otro sistema compuesto por un cuerpo especializado encargado de realizar inspecciones a lo largo del país. Cada prisión tiene asignada una Junta de Inspección Independiente (IMB), adscrita a la Secretaría de Estado, compuesta por voluntarios, lo cuáles no reciben ninguna remuneración (salvo los costos de transporte y manutención). Su función estriba en fiscalizar el trato que reciben los presos en un determinado establecimiento penitenciario, donde sus miembros tienen completa libertad para visitar cualquier parte del establecimiento penitenciario y para entrevistarse en privado con cualquier interno. Posteriormente, realizan un informe que es remitido al director de la prisión o la Secretaria de Estado. Los voluntarios encargados de la inspección son miembros de la comunidad dispuestos a escuchar a los internos con cordialidad y simpatía. Para muchos presos estas organizaciones constituyen uno de los pocos medios donde pueden conversar sobre su vida en la cárcel. Una de las principales críticas de sistema voluntario de fiscalización radica en que no hacen públicos sus informes. También se ha cuestionado los procesos de selección y formación de sus miembros.

Los Inspectores de Prisiones, si bien son financiados por el gobierno, poseen un considerable grado de independencia. Debe destacarse que han tenido un importante impacto en la política penitenciaria en los veinte o treinta años. La razón principal de su éxito estriba que su actitud proactiva a la hora de resolver los problemas detectados en sus inspecciones. Así, tras finalizar la inspección al establecimiento penitenciario realiza una reunión con el director para comunicarle y discutir las quejas o problemas detectados. Los informes no son publicados normalmente entre 12 a 18 semanas después de la inspección $\mathrm{y}$, de esta manera, la administración penitenciaria tiene el tiempo para implementar las reformas necesarias. Y una vez que el informe es publicado las autoridades penitenciarias han comenzado a afrontar los problemas detectados e, incluso, en muchos ya se encuentran resueltos. Así, aproximadamente el $70 \%$ de las recomendaciones son implementadas parcial o completamente antes de que los informes sean publicadas. Se ha estimado que el periodo comprendido entre 2007 y 2008 alrededor de 3.000 recomendaciones fueron implementadas en Inglaterra y Gales. ${ }^{49}$ Sin duda, este mecanismo fomenta que las autoridades penitenciarias aparezcan como responsables y diligentes ante la comunidad y los propios presos.

\footnotetext{
49 OWERS, A., The Salter Lecture. Quaker Socialist Society, 2008.
} http://www.quakersocialists.com/newstalkstextsdocuments 22570.html 
Debido a que los inspectores pueden visitar todas las prisiones a lo largo del país, tienen la capacidad de comparar las condiciones entre los diferentes establecimientos penitenciarios. Además, pueden realizar inspecciones temáticas, donde se físcalice el tratamiento de los diferentes grupos en todo el sistema de prisiones, como por ejemplo, mujeres, jóvenes y minorías étnicas.

Estas inspecciones aspiran a lograr una "prisión saludable", término que implica cuatro elementos claves:

- La prisión debe ser segura.

- Los prisioneros deben ser tratados con respeto y dignidad.

- Los prisioneros deben participar en actividades con una finalidad claramente establecida con anterioridad.

- Estas actividades deben ir destinadas a ayudar a los internos a reinsertarse en la comunidad.

Los inspectores de prisiones realizan sus fiscalizaciones al menos durante una semana y, con frecuencia, sin previo aviso a las autoridades de la prisión. Así, les son entregados una copia de las llaves y tiene libre acceso para examinar cualquier parte del recinto penitenciario. Tienen establecido un programa de entrevistas a los presos que facilita un mayor grado de consistencia en el proceso de fiscalización. Además, tienen acceso a todos los documentos de la prisión y, lo que es más importante, tienen la posibilidad de observar lo que realmente ocurre en las prisiones tanto de día como de noche. De este modo, no estamos ante visitas relámpago sino, por el contrario, ante exhaustivas y detalladas fiscalizaciones de prisiones, tanto públicas como privadas.

Estamos ante una institución pública remunerada pero relativamente independiente que posee credibilidad afianzada en el tiempo. Esto es debido a la naturaleza positiva y constructiva de sus inspectores, en contraposición de actitudes negativas o reactivas en el proceso de reforma penitenciaria. Este cambio en la naturaleza y objetivos en los procesos de fiscalización resulta de vital importancia.

Además resulta evidente que el trabajo de los inspectores de trabajo y de los IMB se complementa mutuamente de diferentes maneras. Así, la combinación de las organizaciones no gubernamentales y la pericia de los inspectores contribuyen a una mejor fiscalización de las prisiones, tanto en cada una de las prisiones como en el sistema nacional penitenciario.

A partir de la experiencia de este tipo de fiscalización en el Reino Unido y en otros países, es necesario destacar varios elementos que deben ser considerados en el desarrollo de un sistema efectivo de fiscalización penitenciaria. Además, de la independencia y del trabajo constructivo, una efectiva fiscalización debería tener las siguientes características:

- Continua

- Regular

- Detallada 
Polit. crim. Vol. 6, № 12 (Diciembre 2011), Art. 3, pp. 296 - 338.

[http://www.politicacriminal.cl/Vol_06/n_12/Vol6N12A3.pdf]

- Sistemática

- Coordinada

- Profesional

- Transparente

Por tanto, una fiscalización penitenciaria no solo debe centrarse en identificar los problemas de la prisión, sino también facilitar y alentar su reforma. De manera especial, el proceso de fiscalización deber ser lo más detallado y compresible posible en el diagnóstico de los problemas a fin de que pueda servir de referencia para el desarrollo de nuevas políticas penitenciarias.

\subsection{Reafirmando la rehabilitación.}

Durante los años setenta el ideal de la rehabilitación fue fuertemente cuestionado en los países anglo-americanos. Se afirmó que los programas de reinserción no habían funcionado y que, en general, no se había cumplido con sus objetivos. Por el contrario, se manifestó que solo servían para ampliar el periodo de confinamiento y el uso de tratamientos coercitivos. Estas críticas recurrentes derivaron en la percepción de que la prisión estaba en "crisis", percepción que, posteriormente, justificó la prisión en términos de incapacitación. ${ }^{50}$

Sin embargo, en las dos últimas décadas ha habido un renovado interés en la implantación y desarrollo de programas de rehabilitación penitenciaria ${ }^{51}$ La política y administración penitenciaria debe mitigar la marginalización y debilitamiento que conlleva la prisión. La mayoría de los presos pertenecen a las clases menos favorecidas, poseen un pobre acervo cultural y, gran parte, sufre problemas como toxicomanías o enfermedades mentales.

Se ha reconocido, incluso, que la prisión puede ser un lugar donde algunas las desigualdades sociales que, previamente poseían los internos antes de ingresar en prisión, pueden ser tratadas. Así, se viene incrementando la implantación de programas de rehabilitación en Gran Bretaña y Estados Unidos que, de entre los más destacados y exitosos, podemos destacar:

- Programas para el tratamiento a la adición de drogas.

- Cursos para el manejo de comportamientos violentos.

- Cursos educacionales básicos de lectura, escritura, etc.

- Tratamientos para los delincuentes sexuales.

- Cursos de capacitación y formación profesional.

${ }^{50}$ BOtTOMS, A. y PRESTON, R., The Coming Penal Crisis. Scottish Academic Press. ZIMRING, F. y HAWKINS, G., Incapacitation: Penal Confinement and the Restraint of Crime. New York: Oxford University Press, 1988.

${ }^{51}$ ROBINSON, G., "Late-Modern Rehabilitation: The Evolution of a Penal Strategy", Punishment \& Society 10 (2008), pp.29-46. 
Junto a estos programas y cursos se ha puesto un especial énfasis en la rehabilitación a través del trabajo, especialmente, aquellos que permiten una capacitación profesional de los internos. Así, la afirmación realizada por parte de la criminología más autorizada en esta materia que la "clásica penología" -relacionada con la asistencia social y la rehabilitación- está siendo rápidamente reemplazada por una "nueva penología" fundamentada en la gestión de riesgos- parece que no ha sido adoptada por las últimas reformas penitenciarias. De hecho, ambas concepciones, la clásica y nueva penología, parecen estar operando simultáneamente $\mathrm{y}$, en algunos aspectos, la aplicación de estos dos modelos ha servido para que se refuercen mutuamente. ${ }^{52}$

La reafirmación de la rehabilitación ha sido justificada principalmente en fundamentos utilitaristas: el incremento de la utilidad social de los presos como consecuencia de la eventual reducción tanto del desempleo como de la reincidencia. También se ha mantenido que los presos tienen el derecho a la rehabilitación por el hecho de que son víctimas de la pobreza y de privaciones de todo tipo y por una inadecuada protección por parte del Estado. La adopción de programas de reinserción social en las cárceles también ha comenzado a ser consideradas como una buena estrategia de gestión que ofrece la posibilidad a los funcionarios de desarrollar otras áreas con inquietudes profesionales, en otras palabras, les permite ser más que simples "guardias".

A pesar de estas ventajas, subsisten serias dudas acerca del papel de la rehabilitación en las prisiones. Estas se centran en el alto grado de reincidencia registrado. El hecho de que la mayoría de los presos regresen a la cárcel es considerado por sus críticos como un indicador del "fracaso" de las estrategias de rehabilitación. Este punto de vista, resulta, sin embargo, simplista y corto de miras. Los programas de rehabilitación penitenciaria que se aplican a los internos que están cumpliendo condenas de uno o dos años de prisión resultan inadecuados para revertir veinte o treinta años de socialización. Tenemos que ser realistas acerca del rendimiento de los programas de rehabilitación. No suelen convertir a peligrosos criminales en santos, pero pueden sí pueden mejorar su comportamiento.

Otro problema de las tasas de delincuencia habitual radica en que raramente miden su intensidad y frecuencia. Así, por ejemplo, alguien que haya estado en prisión por varios delitos graves y cometa una falta o delito menos grave será considerado como un reincidente. De la misma forma, alguien que haya cometido delitos de forma habitual y periódica antes de ingresar en prisión, será también considerado como un reincidente si después de abandonarla comente otro delito, aunque la frecuencia criminal haya disminuido drásticamente.

Ahora bien, no todos los programas de rehabilitación poseen el mismo grado de efectividad. Los Programas Cognitivos de Conducta o terapias de modificación cognitiva de la conducta que fueron desarrollas por primera vez en Canadá, vienen siendo aplicados en numerosos países. Estos programas han sido criticados por parte de la criminología en el sentido de que su diseño confunde entre "pensar correctamente" y "actuar

${ }^{52}$ FEELEY, M. y SIMON, J., "The New Penology: Notes on the Emerging Strategy of Corrections and Its Implications", Criminology 30 (1997), pp. 49-74. 
correctamente". Estos programas equiparan una mayor habilidad cognitiva con el cumplimiento de la ley. Por el contrario, sus críticos sugieren que si estos programas son en la actualidad efectivos en mejorar las capacidades de razonamiento cognitivo es porque quizá producen criminales más inteligentes. ${ }^{53}$ Por esta razón, debemos ser cuidadosos en la elección de los programas y en su posterior evaluación.

En todo caso, el creciente interés por el desarrollo de programas de rehabilitación penitenciaria debe ser valorado de forma positiva, especialmente, aquellos dirigidos a resolver o mitigar los problemas de socialización o incrementar la formación de los presos. A mayor abundamiento, como ha puesto de manifiesto Francis Cullen y Karen Gilbert existen tres razones fundamentales para apoyar la idea de la rehabilitación, ${ }^{54}$ a saber:

1. La rehabilitación es el único fin de la pena que obliga al Estado a ocuparse de las necesidades y bienestar de los presos.

2. La ideología de la rehabilitación supone una racional respuesta a la idea conservadora de que el incremento de la presión punitiva reduce el crimen.

3. La rehabilitación continúa recibiendo un considerable apoyo por de la opinión pública como uno de los principales objetivos del sistema de justicia criminal.

Una situación ideal de rehabilitación penitenciaria supondría la inclusión de programas detallados y completos que también asistan la reinserción de los presos después del cumplimiento de la pena privativa de libertad. Cuando los ex presos no puedan encontrar trabajo o no posean una vivienda o carezcan del soporte de la familia, los resultados positivos derivados de los programas de rehabilitación durante el tiempo de cumplimiento de la condena pueden ser rápidamente anulados. Por tanto, los programas destinados a la reinserción de los ex presos en la comunidad deberían ser estar destinados, en la medida de lo posible, a ayudarles a encontrar un trabajo y una residencia.

\subsection{Penas privativas de libertad de cumplimiento intermitente.}

Cuando pensamos acerca del encarcelamiento tendemos a pensar en internos encerrados veinticuatro horas al día y siete días a la semana. Como hemos visto en relación a la puesta en libertad de los presos en prisión preventiva en Italia, resulta posible dejar en libertad a los presos durante el día para que puedan trabajar o realizar otras actividades, debiendo volver a la prisión en la noche. Varios países como Reino Unido, España, Australia, Nueva Zelanda y Canadá también han implantado la denominada "prisión a tiempo parcial", "pena de privación de libertad de cumplimiento intermitente" o "custodia intermitente".

\footnotetext{
${ }^{53}$ KENDALL, K., "Time to Think Again About Cognitive Behavioral Programmes", en CARLEN, P., (ed) Women and Punishment: The Struggle for Justice. Cullompton: Willan, 2002. PAWSON, R. y TILLEY, N., Realistic Evaluation (Chapter two). London Sage, 1997.

${ }^{54}$ CULLEN, F. y GILBERT, K., Reaffirming Rehabilitation. Cincinnati: Alderson, 1982.
} 
La principal ventaja de la prisión a tiempo parcial radica en que se permite al interno trabajar y mantener las relaciones con su familia y entorno social. Como se ha demostrado, la pérdida del empleo y la ruptura de las relaciones sociales contribuyen al aumento de las tasas de reincidencia.

De las varias formas de la prisión a tiempo parcial que se han desarrollado en el derecho comparado, una de las más comunes es el denominado arresto de fin de semana. Los presos deben cumplir un determinado número de días de prisión en un periodo estipulado en la sentencia. Esta pena normalmente se aplica a delitos no violentos, como hurto, robo con fuerza en las cosas, fraudes y delitos contra la seguridad vial. También es utilizada como pena alternativa a las penas de libertad continua de corta duración y como una manifestación de la responsabilidad penal subsidiaria por impago de una pena pecuniaria.

Un estudio llevado a cabo en el Reino Unido en 2006 encontró que le uso de la custodia intermitente obtuvo el apoyo de los jueces y de diversas agencias penales, como también por los presos que estaban cumpliendo una pena privativa de libertad. La mayoría de los internos seleccionados en este estudio tenían un empleo regular y una familia estable. También se constató que no hubo un número significante de transgresiones de las condiciones impuestas para el cumplimiento de estas penas, ni tampoco un uso abusivo de estas penas o un aumento considerable de los internos sometidos a este tipo de control del poder punitivo (net-widennig). Por el contrario, las limitaciones de la custodia intermitente se centran en el hecho de que solo resulta adecuada para cierto tipo de delincuentes y, gran parte de los problemas, se derivan de una inadecuada aplicación por parte de la administración penitenciaria.

En Canadá la aplicación de este tipo de penas está relacionada principalmente con la reducción del hacinamiento en las prisiones. En Nueva Zelanda, la custodia intermitente fue aplicada inicialmente a presos con edades comprendidas entre 15 y 20 años, pero posteriormente se amplió a todas las edades. Así, en 1995 alrededor del 24\% de los reclusos cumplían una pena de prisión intermitente. Un estudio del Ministerio de Justicia neozelandés ha puesto de manifiesto que este tipo de pena se ha impuesto más a hombres que a mujeres, y tiende a ser aplicada a las minorías étnicas y a miembros de la comunidad indígena. ${ }^{55}$

El desarrollo de la prisión a tiempo parcial, entendida como un cumplimiento de la pena durante las noches o los fines de semana, implica un radical replanteamiento de los fines de las penas en la prisión. Supone considerar a la prisión no, principalmente como un espacio de contención y segregación, sino como una restricción a la libertad que no excluye al delincuente completamente de su familia, lugar de trabajo y comunidad. Esto implica que para cierta categoría de delincuentes la total segregación no resulta siempre necesaria, permitiendo desarrollar un sistema penitenciario más flexible que, al mismo tiempo, esté en condiciones de reducir la tasa de reincidencia. Una de las ventajas generalmente no reconocidas es que esta clase de pena reduce los daños colaterales del encarcelamiento. Un estudio reciente en Estados Unidos ha ratificado el hecho que el impacto de la prisión no solo recayó en el preso, sino también en su familia, parejas o

\footnotetext{
${ }^{55}$ Ministerio de Justicia de Nueva Zelanda, Periodic Detention. http://www.justice.govt.nz/publications
} 
convivientes. En los casos donde un gran número de presos proceden de un barrio, pueblo o lugar determinado, la pena de prisión puede afectar a la economía de toda la comunidad. $^{56}$

\section{A modo de conclusión.}

El presente informe se ha centrado con carácter general en el desarrollo en una reforma constructiva del sistema de prisiones. Sin embargo, debemos poner de relieve que, de acuerdo con un creciente número de investigaciones, existen importantes diferencias entre la encarcelación de hombres y mujeres. La tipología, motivaciones y necesidades de las internas son en algunos casos sustancialmente diferentes respecto de las de los hombres. Por tanto, a la hora de implementar las correspondientes reformas, debe tenerse muy presente estas diferencias y reconocer que las prioridades y procesos de implantación resultan significativamente diferentes entre hombres y mujeres. ${ }^{57}$

Una especial atención, también requiere la regulación de los menores infractores. La ubicación de los jóvenes infractores en cárceles de adultos es considerado ampliamente una política equivocada $\mathrm{y}$, por esta razón, la mayoría de los países occidentales han desarrollado un sistema de justicia autónomo, que pretende evitar que los jóvenes infractores «crezcan separados del crimen» y apartados de las "escuelas del crimen". En muchos países solo se imponen penas de prisión a los jóvenes infractores como último recurso, es decir, cuando se han agotado todas las penas o medidas alternativas, o sea, medidas de una marcada finalidad resocializadora y que no implican una privación de libertad. El Convenio de Naciones Unidas sobre los Derechos del Niño, ratificado por todos los países, salvo Estados Unidos y Somalia, establece unas directrices con el fin de proteger a los jóvenes dentro del propio sistema de justicia criminal. ${ }^{58}$

En el mismo sentido, una especial consideración requiere la situación de las minorías étnicas y comunidades indígenas. Se estima que la población indígena en Latinoamérica asciende a cincuenta y cinco millones de personas, donde la mayoría residen en México, Guatemala, Ecuador, Perú y Bolivia. Así, por ejemplo, en Bolivia la población indígena constituye el $67 \%$ de la población, o en Guatemala y Ecuador asciende al 40\%. Aunque en general no se ha constatado una sobrerepresentación de las comunidades indígenas en la población penitenciaria, existen cuestiones muy relevantes sobre la naturaleza y características de los delitos por los cuales son encarcelados. Las investigaciones realizadas en Europa y Estados Unidos ponen de manifiesto la particular vulnerabilidad de las minorías étnicas más pobres en relación, no solo respecto a las mayores posibilidades de ser detenidos y encarcelados, sino también en cuanto a las mayores

\footnotetext{
56 MAUER, M. y CHESNEY- LIND, M., Invisible Punishment: The Collateral Consequences of Mass Imprisonment. New York: The New Press, 2002.

57 Véase CARLEN, P. y WORRALL, A., Analysing Women's Imprisonment. Cullompton: Willan, 2004. NÚÑEZ, D., (2008) "Woman, Prison and Human Rights: An Outlook of the Current Situation in Latin America", en CARRANZA, Crime, Criminal Justice, cit. n 8. SALLA/BALLESTEROS, cit. nota $n^{\circ} 31$.

${ }^{58}$ Dentro de los centros de detención juvenil también se presentan graves problemas con el uso de armas y la pertenencia a bandas. Véase Human Rights Watch, Brazil "Real Dungeons", cit. nota ${ }^{\circ} 23$. Human Rights Watch, In the Dark, cit. nota ${ }^{\circ} 47$.
} 
MATTHEWS, Roger. "Una propuesta realista de reforma para las prisiones de Lationamérica".

dificultades de acceder al asesoramiento legal. ${ }^{59}$

Si examinamos la situación de las mujeres, jóvenes y minorías étnicas, la problemática de las bandas, el hacinamiento y los problemas de seguridad en las prisiones latinoamericanas, resulta compresible tener una visión pesimista $\mathrm{y}$, en algunas ocasiones, cínica acerca de la viabilidad de una reforma penitenciaria. Pero contra esta opinión, hemos visto que importantes reformas han sido implantadas, no solo en países occidentales, sino también en países como Rusia, India, Canadá o los países escandinavos que, sin perjuicio de que su gestión esté todavía muy lejos de ser perfecta, han alcanzado significativos avances en los últimos años. Incluso en Norteamérica, donde la tasa de encarcelación es cinco o seis veces superior que la mayoría de los países, podemos constatar una reducción de la población penitenciaria y un desarrollo de políticas penales de corte liberal. ${ }^{60}$

La reforma penitenciaria en Latinoamérica no es solo un mero deseo o aspiración, sino que es posible de llevar a cabo. Algunas de las reformas que hemos sugerido en este informe pueden involucrar una inversión adicional de gastos y recursos. En algunos casos, una pequeña inversión puede generar grandes ganancias. También, debemos tener presente que los costos financieros involucrados suelen ser sobrevalorados respecto de los beneficios individuales, sociales y políticos que ha logrado la reforma penitenciaria. Incluso, algunas de ellas pueden reducir el gasto público. En todo caso, la mayoría de ellas solo requiere un cambio de estrategia y de organización. Aun, la pobre situación de muchas prisiones en muchos países latinoamericanos, paradójicamente, facilita la posibilidad de implantar positivas y efectivas reformas.

Algunas de las reformas que hemos sugerido en este informe pueden involucrar una inversión adicional de gastos y recursos y la mayoría de ellas requerirá cambios de estrategia y organización. Debemos tener presente que, en algunos casos, una pequeña inversión puede generar unas grandes ganancias. Los costos financieros involucrados suelen ser sobrevalorados respecto a los beneficios individuales, sociales y políticos que ha logrado la reforma penitenciaria. Incluso, algunas de ellas pueden reducir el gasto público.

Resulta importante señalar que una reforma eficaz debe involucrar no solo a los representantes políticos y a las agencias directamente relacionadas con el sistema penitenciario, sino también a toda la comunidad. Estudios sobre la opinión pública sugieren que los ciudadanos no solo quieren ver la aplicación de la justicia retributiva, sino también un sistema de justicia criminal profesional que trabaje para incrementar la seguridad pública, reducir el crimen y la victimización y asegurar que los presos que abandonan la prisión no suponen una mayor carga o amenaza a la comunidad de la que

\footnotetext{
${ }^{59}$ KALMTHOUT, A. VAN DER MEULEN, F. y DUNKEL, F., Foreigners in European Prisons (2 Vols.). Wolf, 2007. Respecto de la encarcelación de la población originaria en Latinoamérica, véase, ESTRADA, D., "Latin America: Justice Disserved for Indigenous Prisoners". http://upsidedown world.org/main/chilearchives-34/1152, 2008.

${ }^{60}$ JACOBS, Downsizing Prisons, cit. nota ${ }^{\circ} 24$.
} 
tenía cuando ingresaron en prisión. ${ }^{61}$

La reforma de la prisión se encuentra en un continuo proceso como consecuencia de los constantes cambios sociales, políticos, económicos y administrativos. Por tanto, el desarrollo y mantenimiento de instituciones penales menos dañosas constituye también un proceso en continuo desarrollo. La experiencia e historia han demostrado que los esfuerzos en reformar las prisiones pueden realmente merecer la pena. Varios países latinoamericanos se han embarcado ya en una reforma estructural y coordinada de las prisiones y, en algunos casos, con efectos positivos. Necesitamos aunar todos nuestros esfuerzos para defender los derechos humanos, alcanzar una comunidad segura y promover la justicia social.

\section{BIBLIOGRAFÍA}

Amnesty International (2007) Index, AMR 19/023/2007.

BBC News, Ten Die in Venezuela Prison Gang Battle, 2010, http://www.bbc.co.uk/news/world-latin-amaerica-11439683

BOLL, M., Plea Bargaining and Agreement in the Criminal Process: A Comparison Between Australia, England and Germany. Verlag, 2009.

BOTTOMS, A. y PRESTON, R., The Coming Penal Crisis. Scottish Academic Press, 1991.

BOTTOMS, A., "Interpersonal Violence and Social Order in Prisons", en: TONRY, M., y PETERSILIA, J., (eds.) Prisons. Chicago: University of Chicago Press, 1999.

CARLEN, P. y WORRALL, A., Analysing Women's Imprisonment. Cullompton: Willan, 2004

CARRANZA, E., "Prison Privatization in Latin America", en CARRANZA, E., (ed.) Crime, Criminal Justice and Prison in Latin America and the Caribbean. ILANUD. Costa Rica, 2008, http://www.ilanud.or.cr

CLARENDON y LIVINGSTONE, S., "The Changing Face of Prison Discipline", en: PLAYER, E., y JENKINS, M., Jenkins (eds.) Prison After Woolf: Reform Through Riot. London: Routledge, 1994.

COHEN, M. y RUBIO, M., "Violence and Crime in Latin America", documento preparado para la Consulta de San José, 2007, http://www.iadb org/document.cfm?id=1186239

COHEN, S., Visions of Social Control. Cambridge: Polity, 1985.

COOKE, D., "Containing Violent Prisoners: An Analysis of the Barlinnie Special Unit", British Journal of Criminology, Vol. 29, 우 2 (1989).

COYLE, A., A Human Rights Approach to Prison Management. London: International Centre for Prison Studies, 2002.

CRAWLEY, E., Doing Prison Work: The Public and Private Lives of Prison Officers. Cullompton: Willan, 2004.

\footnotetext{
${ }^{61}$ Véase, MATTHEWS, R., "The Myth of Punitiveness", Theoretical Criminology Vol. 9, No 2 (2005), pp. 175-202. DURHAM, A., "Public Opinion Regarding the Sentences for Crime. Does it Exist?", Journal of Criminal Justice Vol. 21, № 1 (1993), p.1-11.
} 
MATTHEWS, Roger. "Una propuesta realista de reforma para las prisiones de Lationamérica".

CULLEN, F. y GILBERT, K., Reaffirming Rehabilitation. Cincinnati: Alderson, 1982.

DEL OLMO, R., "The State of Prisons and Prisoners in Four Countries in the Andean Region", en: WEISS, R. y SOUTH, N., (eds.) Comparing Prison Systems. Amsterdam: Gordon and Breach Publishers, 1998.

DONZELOT, J., The Policing of Families. London: Hutchinson, 1979.

DURHAM, A., "Public Opinion Regarding the Sentences for Crime. Does it Exist?" Journal of Criminal Justice Vol. 21, $\mathrm{N}^{\circ} 1$ (1993), pp. 1-11.

EDGAR, K., O'DONNELL, I. y MARTIN, C., Prison Violence: The Dynamics of Conflict Fear and Power. Cullompton: Willan, 2003.

ESTRADA, D., "Latin America: Justice Disserved for Indigenous Prisoners". http: //upsidedown world.org/main/chile-archives-34/1152, 2008.

FEELEY, M. y SIMON, J., "The New Penology: Notes on the Emerging Strategy of Corrections and Its Implications", Criminology Vol. 30, N 4 (1992), pp. 49-74.

FOUCAULT, M., Discipline and Punish: The Birth of the Prison. London: Allen Lane, 1977.

Gaceta Penitenciaria Nº 08 (2011), Ministerio de Gobernación.

GANGAN, S., "Mararashtra Nod for 100 Fast Track Courts". Daily News and Analysis, Marzo 16, 2011.

GARLAND, D., Punishment and Welfare: A History of Penal Strategies. Aldershot: Gower, 1985.

GRAHAM, D., "Fast Track Courts to Handle Rape Cases in the Capital", Centre For Social Research, New Delhi, India, 2011.

GRAMSCI, A., Prison Notebooks. New York: Nowell, Smith and Hoare, 1971.

HAMAI, K. "Prison Population in Japan: Stable for 30 Years", en TONRY, M., (ed.) Penal Reform in Overcrowded Times. Oxford University Press, 2001.

HARDING, R., Private Prisons and Public Accountability. Buckingham: Open University Press, 1997.

Home Office Border Agency, Country of Origin Information Report. India, 2010.

HOUGH, M., ALLEN, R. y SOLOMON, E., Tackling Prison Overcrowding. Bristol: The Policy Press, 2008.

HUCKLESBY, A., HAGlEY-DICKENSON, L., Prisoner Resettlement: Policy and Practice. Cullompton: Willan, 2007.

HUCKLESBY, A., y WINCUP, E., Drug Interventions in Criminal Justice. Open University Press, 2010.

Human Rights Watch, World Report. Argentina, 2011, http://www.hrw.org/en/worldreport-2011/argentina

Human Rights Watch, World Report. Chile, 2009, http://www.hrw.org/en/worldreport/2009/chile

Human Rights Watch, World Report. Venezuela, 2011, http://www.hrw.org/en/worldreport-2011/venezuela

Human Rights Watch, In the Dark: Hidden Abuses Against Detained Youths in Rio de Janeiro. Vol. $17 \mathrm{~N}^{\circ} 2$ (B), Junio 2005.

International Bar Association, One in Five: The Crisis in Brazil's Prisons and Criminal Justice System. Human Rights Institute Report, 2010.

JACOBS, J., Stateville: The Penitentiary in Mass Society (chapter 6). Chicago: University of Chicago Press, 1977. 
Polit. crim. Vol. 6, No 12 (Diciembre 2011), Art. 3, pp. 296 - 338.

[http://www.politicacriminal.cl/Vol_06/n_12/Vol6N12A3.pdf]

JACOBS, J., "Prison Reform Amid the Ruins of Prisoners' Rights", en TONRY M., (ed.) The Future of Imprisonment: Oxford University Press, 2004.

JACOBS, M., Downsizing Prisons; How to Reduce Crime and End Mass Incarceration. New York University Press, 2005.

KALMTHOUT, A., VAN DER MEULEN, F. y DUNKEL, F., Foreigners in European Prisons (2 Vols.). Wolf, 2007.

KENDALL, K., "Time to Think Again About Cognitive Behavioral Programmes", en CARLEN P., (ed.), Women and Punishment: The Struggle for Justice. Cullompton: Willan, 2002.

KING, R. y McDERMOTT, K., The State of Our Prisons. Oxford, 1995.

KNOX, G., The Problem of Gangs and Security Threat Groups in American Prisons. National Gang. Research Centre, 2005.

MATTHEWS, R., "Alternatives to Prison: A Realist Approach", en CARLEN, P., COOK, D., (eds.) Paying for Crime. Bristol: Open University Press, 1989. , "Developing a Realist Approach to Penal Reform", en LOWMAN, J. y MacLEAN (eds.) Realist Criminology: Crime Control and Policing in the 1990s. Torono: University of Toronto Press, 1992. "The Myth of Punitiveness", Theoretical Criminology Vol. 9, $\mathrm{N}^{\circ} 2$ (2005), pp. 175-202.

, "Realist Criminology Revisited", McLAUGHLIN E., y NEWBURN, T., (eds.) The Sage Handbook of Criminological Theory. London: Sage, 2010.

"Rethinking Penal Policy: Towards a Systems Approach", en: MATTHEWS, R., YOUNG, J., (eds.) The New Politics of Crime and Punishment. Cullompton: Willan, 2003.

- Pagando Tiempo: Una Introducción a la Sociología del Encarcelamiento: Ediciones Belllaterra, 2003.

MAUER, M. y CHESNEY-LIND, M., Invisible Punishment: The Collateral Consequences of Mass Imprisonment. New York: The New Press, 2002.

MANZ, B., Central America: Patterns of Human Rights Violations. Writenet. University of California: Berkeley, 2008.

MCEVOY, K., Paramilitary Imprisonment in Northern Ireland: Resistance, Management and Release; Oxford University Press, 2011.

McGUIRE, J., What Works: Reducing Reoffending. Chichester: Wiley, 1995.

McIVOR, G., "Reparation and Restorative Approaches", en: BOTTOMS, A., REX, S., y ROBINSON, G., (eds.) Alternatives to Prison: Options for an Insecure Society. Cullompton: Willan, 2004.

Ministry of Justice New Zealand. Periodic Detention. http://www.justice.govt.nz/publications

NATHAN, S., "Prison Privatization: International Developments and Issues and the Implications for Latin America", en CARRANZA, E., (ed.), Crime, Criminal Justice and Prison in Latin America and the Caribbean. ILANUD. Costa Rica, 2008, http://www.ilanud.or.cr

NÚÑEZ, D., "Woman, Prison and Human Rights: An Outlook of the Current Situation in Latin America", en: CARRANZA E., (ed.), Crime, Criminal Justice and Prison in Latin America and the Caribbean. ILANUD. Costa Rica, 2008, http://www.ilanud.or.cr 
MATTHEWS, Roger. "Una propuesta realista de reforma para las prisiones de Lationamérica".

Office of National Drug Control Policy, Painting the Current Picture: A National Report Card on Drug Courts and Other Problem Solving Programs in the United States, 2010. http://www.whitehousedrugpoliciy_gov/enforce/drug_court.html

OWERS, A., The Salter Lecture. Quaker Socialist Society, 2008. http://www.quakersocialists.com/newstalkstextsdocuments 22570.html

PARENTI, C., Lockdown America; Police and Prisons in the Age of Crisis. London: Verso, 1999.

PARKER, L., Restorative Justice in Prison: Report from the UN Crime Congress, 2010. http://www.restorativejustice,org/RJOB/rjprisonscongress

PARKER, M., Dynamic Security: The Democratic Therapeutic Community in Prison. London: Jessica Kingsley, 2007.

PAWSON, R. y TILLEY, N., Realistic Evaluation (Chapter two). London: Sage, 1997.

PETERSILIA, J., When Prisoners Come Home: Parole and Prisoner Reentry. Oxford University Press, 2003.

PIACENTINI, L., Surviving Russian Prisons. Cullompton: Willan, 2004.

Preliminary Report by the Special Rapporteur on Extrajudicial, Summary or Arbitray Executions. Philip Alston Addendum, Mission to Brazil. November 2007. UN Doc.A/HRC/8/3/Add.414 May 2008.

ROBINSON, G., "Late-Modern Rehabilitation: The Evolution of a Penal Strategy", Punishment \& Society Vol. 10, N 4 (2008).

RUSCHE, George (et alii), Punishment and social structure. New York: Columbia University Press, 1939.

RUSCHE, G. y KIRCHHEIMER, O., Punishment and Social Structure. New Brunswick: Transaction Books, 2003.

SAlvatore, R. y AGUIRRE, C., The Birth of the Penitentiary in Latin America. University of Texas Press, 1996.

SALlA, F. y BALleSteros, P., Democracy Human Rights and Prison Conditions in South America. University of Sao Paulo, Brazil, 2009. http://www.udhr60.ch

SAYER, A., Realism in Social Science. London: Sage, 2001.

SPARKS, R., BOTTOMS, A. y HAY, W., Prisons and the Problem of Order: Oxford; Clarendon, 1996.

SYLVESTRE, M-E., "The Vicious Cycle of Violence: Prison Riot at the Benfica House of Detention in Rio de Janeiro", The Harvard Review of Latin America, 2005.

TOMLINSON, M., "Imprisoned Ireland”, en: RUGGERIO, V., RYAN, M. y SIM, J. (eds.) Western European Penal Systems: A Critical Anatomy. London: Sage, 1995.

Transnational Institute, System Overload: Drug Laws and Prisons in Latin America. 2010.

UGGLA, F., "The Ombudsman in Latin America", Journal of Latin American Studies, Vol. 36, N³ (2004), pp. 36-50.

UN News Centre, UN Rights Expert Urges Uruguay to End Appalling Prison Conditions, 2009.

UNGAR, M. y MAGOLINI, A., "Latin America's Prisons: A Crisis of Criminal Policy and Democratic Rule", en: BERGMAN M., WHITEHEAD, L., (eds.) Criminality, Public Security and the Challenge to Democracy in Latin America. Indiana: University of Notre Dam Press, 2009.

UNGAR, M., "Prisons and Politics in Latin America", Human Rights Quarterly Vol. 25, 
Polit. crim. Vol. 6, № 12 (Diciembre 2011), Art. 3, pp. 296 - 338.

[http://www.politicacriminal.cl/Vol_06/n_12/Vol6N12A3.pdf]

$\mathrm{N}^{\circ} 4$ (2003), pp. 909-34.

VOGEL, M., Coercion and Compromise: Plea Bargaining, The Courts and the Making of Political Authority. Open University Press, 2007.

WALKER, J., International Experience of Drug Courts. The Scottish Executive Scottish Research Unit, Edinburgh, 2001.

ZIMRING, F., y HAWKINS, G., Incapacitation: Penal Confinement and the Restraint of Crime. New York: Oxford University Press, 1988. 